\title{
Emerging era of microneedle array for pharmaceutical and biomedical applications: recent advances and toxicological perspectives
}

\author{
Shailesh Dugam ${ }^{1}$, Rahul Tade ${ }^{2}$, Rani Dhole ${ }^{3}$ and Sopan Nangare ${ }^{2^{*}}$ (D)
}

\begin{abstract}
Background: Microneedles (MNs) are the utmost unique, efficient, and minimally invasive inventions in the pharmaceutical field. Over the past decades, many scientists around the globe have reported MNs cautious because of their superb future in distinct areas. Concerning the wise use of MNs herein, we deal in depth with the present applications of MNs in drug delivery.

Main text: The present review comprises various fabrication materials and methods used for MN synthesis. The article also noted the distinctive advantages of these MNs, which holds huge potential for pharmaceutical and biomedical applications. The role of MNs in serving as a platform to treat various ailments has been explained accompanied by unusual approaches. The review also inculcates the pharmacokinetics of MNs, which includes permeation, absorption, and bioavailability enhancement. Besides this, the in vitro/in vivo toxicity, biosafety, and marketed product of MNs have been reviewed. We have also discussed the clinical trials and patents on the pharmaceutical applications of MNs in brief.
\end{abstract}

Conclusion: To sum up, this article gives insight into the MNs and provides a recent advancement in MNs, which pave the pathway for future pharmaceutical and biomedical applications.

Keywords: Microneedles, Fabrication of MNs, Pharmaceutical and biomedical applications, Pharmacokinetics of MNs, Biosafety of MNs, Clinical trials and patents

\section{Background}

Several approaches to the drug delivery system have been adopted for the administration of the drug into the body. Out of this, the oral drug delivery system has been widely accepted due to its effortless administration and more patient compliance [1]. Meanwhile, many studies are looking into an oral or conventional route of administration. It leads to the conclusion that they were not fulfilling the appropriate purpose of the medication. Therefore, for satisfying the needs, other routes of

\footnotetext{
* Correspondence: snangareopan@gmail.com

${ }^{2}$ Department of Pharmaceutical Chemistry, H. R. Patel Institute of Pharmaceutical

Education and Research, Shirpur-425405, Dhule, Maharashtra, India

Full list of author information is available at the end of the article
}

administration have been developed after humongous research. The transdermal drug delivery system (TDDS) is among them, in which drugs are administered through external epithelia, i.e., stratum corneum (SC) [2]. However, this outermost layer of skin acts as a principal barrier for topically applied medications. It allows the transfer of drug(s) having molecular weight $<500 \mathrm{Da}$, adequate lipophilicity, and low melting point. Thus, to overcome the aforesaid limitations in the last earlier decades, we are dealing with the use of micro and nanotechnologies in drug delivery aspect to get the desired outcomes of the formulations/system as per our compendial requirements for intended use application $[1,3]$. These pioneered systems are preferred because they 
have several advantages over the conventional route of drug delivery [1,3-8], even though passing the drug particles through different skin barriers leads to developing a measurable hurdle in drug delivery [3]. In TDDS, drugs can be administrated to different pathways like transcellular and intracellular routes. In both pathways, the drug is delivered to the targeted site or the site of action by simple diffusion. The other important pathway is by microneedling through microchannels. Gerstel and Place firstly invented microneedle technology for the conveyance of drugs in 1971. At that time, inventors Gerstel and Place termed MNs as "puncturing projections." However, the first prosperous attempts on MNs emerged in the 1990s [4]. These MNs are accomplished with several charismatic advantages like easy to use, easy to fabricate as per compendial requirements, and reduces the pain and irritation without extensive rupture to the skin. It offers a faster healing rate than conventional methods, bypasses the first-pass metabolism of the drug, and therefore can achieve required pharmacokinetics and pharmacodynamics response, and pretends to explore MNs as an excellent tool for the intended use. Fascinatingly, they are also applicable for quicker delivery of drug substances, administration of high molecular weight molecules, targeted and controlled drug delivery, etc.; due to which, they are widely accepted for pharmaceutical applications. Although the MNs suffer from some limitations like the necessity of careful handling, hindrance in the drug delivery due to some external factors like hydration of skin, damaging the veins due to the repetitive administration, or chances of injuring the skin while removing the patch if the MNs are broken. MNs are micron-sized needles that are used to open holes into the skin to create microchannels for the subsequent delivery of drugs. Generally, the MNs move in the epidermal layer of skin deprived of touching the nerves and consequently conveying the medicament transdermally without pain for both low and high molecular weight. MNs are $100 \mu \mathrm{m}$ long, 1-50 $\mu \mathrm{m}$ wide at the tip, and about 50 to $300 \mu \mathrm{m}$ at the base [1,3]. Generally, MNs consist of a plurality of microprojections, ranging from 25 to $2000 \mu \mathrm{m}$ in height, along with different shapes, which are attached to the base support [5].

MNs are fabricated from a wide diversity of materials, viz., metal, polymer, glass, silicon, ceramic, hydrogel, and sugar [5]. Revolution in the microelectronics industry launches the various microfabrication technology tools that enabled the advancement in the manufacturing facilities necessary to produce microconduits in MNs [6]. In the earlier decades, the fabrication of diverse types of MNs via different techniques for the enhancement in the delivery of drugs and compatibility with a wide variety of physicochemical properties is extensively researched and has been demonstrated in in vitro, ex vivo, and in vivo experiments [7]. But still, its overwhelming applications in the field of cellular delivery, targeted delivery, DNA vaccine delivery, protein delivery, systemic delivery, etc. are not explored that much $[8,9]$. Thus, in this present review, more emphasis has been given in depth to the existing applications of MNs in the release of active agent. Herein, we also deal with recent advancements made in fabrication materials and methods used for MN synthesis for intended use applications and discussed the variety of MNs. The review also inculcates the pharmacokinetics of MNs, which includes permeation, absorption, bioavailability enhancement, toxicity, and biosafety of MNs. The patent and clinical trials on pharmaceutical applications of MNs have been reviewed. Thus, this article gives insight about the MNs and also provides the recent advancement in MNs, which pave the pathway for future pharmaceutical application

\section{Main text}

The material meant for the fabrication of MNs

Several types of material have been used for the fabrication/manufacturing of MNs. It includes polymeric materials (natural, biodegradable, non-biodegradable) and metals [10-12]. The general criteria for polymers, metals, and metalloids include good biocompatibility and mechanical properties [13]. In addition, it should be stable and should show chemical resistance. It should contain attractive physical properties that can make it a versatile material for pharmaceuticals as well as biomedical applications [12]. Furthermore, it should be socioeconomic and safe for human health. Also, in most of the cases especially polymeric MNs or dissolvable MNs, the material should regulate the drug release rate (viz., controlled/sustained) [14]. In addition, they should show the admirable degradation at physiological conditions. The material should possess an acceptable molding ability. Despite the stability, the selected material should be highly stable in the fabrication and packaging process also [12]. Instead, the dissolving, hydrogel-forming, and biodegradable MNs contain polymeric material. It should follow the acceptance criteria of MNs [15]. Herein, we have summarized the types of materials with mostly acceptable examples (Table 1).

\section{Types of MNs}

MNs are classified into two different groups based on the fabrication strategy, i.e., in-plane MNs and outplane MNs. Concerning the facts of drug delivery, the MNs are classified as solid MNs, hollow MNs, coated $\mathrm{MNs}$, dissolving MNs, and hydrogel-forming MNs (Fig. 1). 
Table 1 Material used for the fabrication of smart MNs

\begin{tabular}{llll}
\hline Polymers & & & Metals/metalloids \\
\hline Natural & Biodegradable & Non-biodegradable & Silicon \\
\hline CS & PLGA & Alginic acid & Titanium \\
CMC & PLA & Gantrez AN-139 & Stainless steel \\
Dextran & PVP & Polyvinyl acetate & Palladium-cobalt alloys \\
Zein & Polyglycolic acid & PVA & Palladium \\
Galactose & Polycarbonate & Carbopol 971 P-NF & Nickel \\
Starch (thermoplastic) & Polyvinylpyrrolidone & Polyetherimide & \\
\hline
\end{tabular}

\section{Solid MNs}

Generally, solid MNs are performed by creating the holes in the SC layer of skin and are applied before the application of dosage form and detached thereafter or the drug may be coated onto the needles [16]. After removal of solid MNs, it leads to the formation of temporary microchannels where a drug can be placed in the form of cream, gel, solution, or transdermal patches. These microchannels recover soon afterward so that there is no secondary infection $[16,17]$. The drug penetrates through the skin via microchannels and reaches to applicable site. In addition, solid MNs help to boost the transdermal transmission of different biologicals or therapeutics, which cannot be conveyed by passive diffusion. Solid MNs can increase the transdermal absorption of the small molecules by up to 4 folds. Additionally, these solid MNs are used to convey the bulky molecular weight compounds [17]. Solid MNs are made up of different metals like palladium, stainless steel, cobalt alloy, nickel, and silicon (Table 2). Besides, different materials are used for the formulation of solid MNs like maltose, sucrose ceramic, non-biodegradable, and biodegradable polymers [5]. Even though the drug delivery through solid MNs is a much considerable system, it encounters

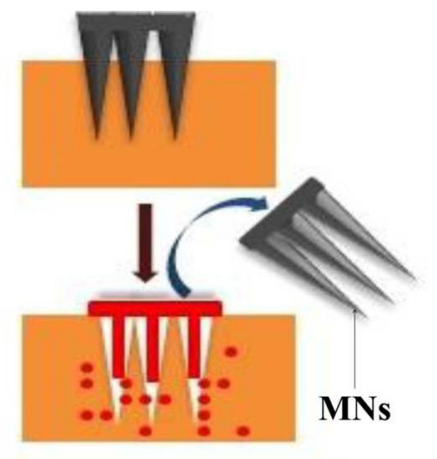

Solid MNs

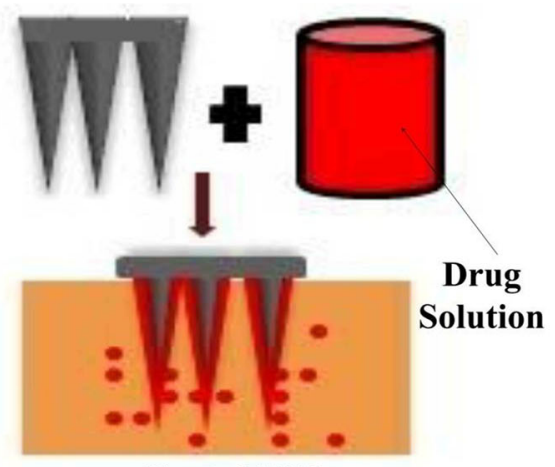

Coated MNs

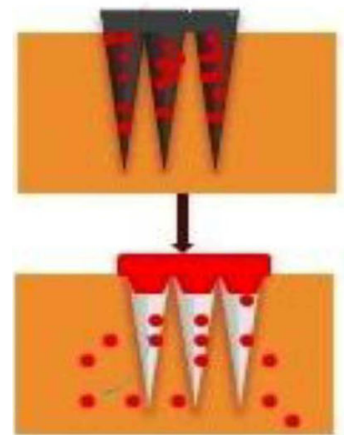

Dissolving MNs

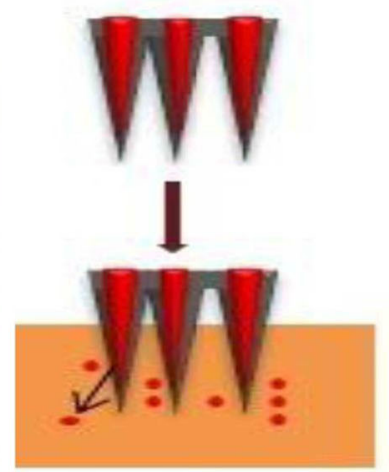

Hollow MNs

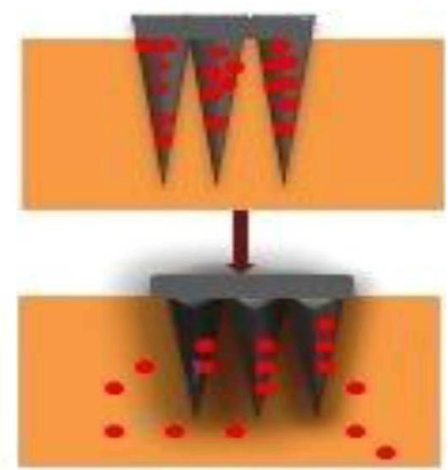

Swellable MNs

Fig. 1 Types of MNs based on drug delivery approach 
Table 2 Fabrication techniques for a variety of MNs

\begin{tabular}{|c|c|c|c|}
\hline $\begin{array}{l}\text { Sr. } \\
\text { No. }\end{array}$ & $\begin{array}{l}\text { Type } \\
\text { Solid MNs }\end{array}$ & Method of construction & Ref. \\
\hline \multirow[t]{3}{*}{ 1.1.1. } & Silicon MNs & $\begin{array}{l}\text { Microelectromechanical systems (MEMS) techniques, thin-film deposition on a substrate, chemical vapor deposition on } \\
\text { a substrate, Silicon dry-etching process, Isotropic etching, etc. }\end{array}$ & $\begin{array}{l}{[17,} \\
18]\end{array}$ \\
\hline & Metal MNs & $\begin{array}{l}\text { Three-dimensional laser ablation, laser cutting (stainless less), metal electroplating methods (palladium), wet etching } \\
\text { photochemical etching (titanium), etc. }\end{array}$ & $\begin{array}{l}{[19-} \\
21]\end{array}$ \\
\hline & Ceramic MNs & Ceramic micro molding and sintering lithography, etc. & [5] \\
\hline 2. & Coated MNs & Dipping or spraying, layer-by-layer (LbL) coating techniques & [5] \\
\hline 3. & Hollow MNs & $\begin{array}{l}\text { Deep reactive ion etching of silicon, deep X-ray photolithography, wet chemical etching, and microfabrication, Inte- } \\
\text { grated lithographic molding technique, etc. }\end{array}$ & [5] \\
\hline 4. & $\begin{array}{l}\text { Dissolving } \\
\text { MNs }\end{array}$ & Micromolding & [5] \\
\hline 5. & $\begin{array}{l}\text { Polymeric } \\
\text { MNs }\end{array}$ & Photolithography, micro molding, casting, hot embossing, injection molding, investment molding, etc. & $\begin{array}{l}{[5,} \\
22- \\
24]\end{array}$ \\
\hline
\end{tabular}

some drawbacks, viz., the necessity of a two-stage process, the placement of sharp bio-hazardous residues, and the tendency of skin to self-regenerate which heals itself and inhibits transmission of molecules via microspores [25]. To overcome the aforesaid limitations, the researcher tested a co-drug strategy for the continuous delivery of a therapeutic drug, across the skin treated with solid MNs [26].

\section{Coated MNs}

These are the solid array of MNs made up of different metals and silicon and then further coated with a drug or mixture of drugs. After applying coated MNs on the skin, the coated material gets absorbed into the skin followed by penetration. MN coating is considered a prominent technique for quick and instant bolus delivery of molecules [26]. In addition, appropriate coating and proper drying of drug or surface modification of smart MNs may enhance their long-term stability. Dip coating and casting techniques are most wisely applied for the production of coated MNs [27]. Depending on physicochemical adsorption, mechanism of chemical processing and surface alteration, numerous techniques, viz., dip coating, spray coating, and inkjet printing, brushing, electrohydrodynamic atomization, gas-jet drying, are used to produce coated MNs [17]. Gill designed MNs along with central openings termed "pockets" that were prepared in aqueous or organic solvents. The flexibility of the MN coating technique was showed by coating curcumin (hydrophobic molecule) and bovine serum albumin (BSA)/insulin (model proteins) using suitable solvent-based coating solutions [28]. Recently, transcutaneous vaccine delivery was investigated for the feasibility of fabrication and antigen delivery using coated MNs by Bhatnagar et al. [29]. As the layer of coating reduces, the mechanical strength as well as the sharpness of the MNs reduces, which confined the decrease in drug load on the surface of the MNs.

\section{Dissolving MNs}

In the last few years, concerning the applicability of MNs, they are prominently used for the delivery of various kinds of compounds ranging from low molecular weight drugs to proteins, vaccines, and plasmid DNA. They are fabricated using common materials depicted in Table 2. The literature survey evinced that the researcher increased the skin penetration of therapeutics like docetaxel by applying elastic liposomes to the skin and that was penetrated with silicon-based MNs, while some were coated with DNA using a water-soluble formulation. However, their expensive material costs or an unwanted two-step administration method limits the use of these types of MNs [30]. To overcome these previously mentioned limitations, a biodegradable polymer or water-soluble carbohydrates have been utilized lately for the fabrication of MNs. Miyano et al. recorded the first dissolvable MNs in 2005. Also, to minimize the potentially hazardous sharp waste, the principle of poke and release-based dissolvable MNs was created, [30]. These MNs were entirely degraded/dissolved into the skin interstitial fluids and in that way releasing encapsulated active agent [30, 31]. Besides, many biopharmaceutical compounds, including small-molecular-weight heparins, insulin, leuprolide acetate, erythropoietin, and human growth hormone, were explicitly used to meet different medical needs [32]. Dissolving MNs can be manufactured from various materials like polylactic acid (PLA), hyaluronic acid (HA), poloxamer, silk fibroin (SF), polyvinyl alcohol (PVA), polyvinyl pyrrolidone (PVP), and poly(lactic-co-glycolic acid) (PLGA) [17]. Nevertheless, the advances of dissolving MNs furnish the list of obstacles, viz., manufacture of smart MNs at elevated temperatures, admirable activities of their heat-liable cargoes 
such as peptides, and protein losses. In addition, carbohydrate-based MNs deformed readily under relatively humid conditions, which negatively affected the mechanical strength of the needles. Thus, dissolving MNs are drug delivery systems with the potential to administer the therapeutics required to fulfilling these requirements [33].

\section{Hollow MNs}

The method of drug delivery through hollow MNs involves the process of injection of drugs through a hollow bore, which is situated at the center of the needle. As the MNs are impaled into the skin, the hollow bore present inside bypasses the SC layer by creating microchannels into the different layers of the epidermis [1]. The hollow bore enhances the transmission of activity via the needles either by diffusion method or by the pressure-driven flow. This method of approach is more reminiscent of an injection than a patch. It is used mostly for high molecular weight substances like proteins, vaccines, and oligonucleotides [34]. Drugs can be distributed as needed constantly, without the removal of drug patches as in solid MNs. The hollow MNs were manufactured with a choice of methods listed in Table 2 [17]. Jiang et al. also showed the intrascleral distribution of the model drug, sulforhodamine, and combinations of microparticles/nanoparticles (NPs) using hollow glass MNs. For this analysis, hollow MNs were made from a micropipette tube with borosilicate cylindrical glass. These devices were produced using various materials such as silicone, rubber, glass, polymers, metals, and ceramics depicted in Table 2 [35]. Hollow MNs were commonly used to deliver insulin, to inject vaccines, protein antigen, nucleic acid, huge molecular weighted substances, and other therapies such as pilocarpine. Among them, vaccination is the most popular application of hollow MNs [36].

\section{Hydrogel-forming MNs}

Traditional soluble MN arrays or biodegradable MN arrays are furnished from a kind of dissolving/degradable polymers. These $\mathrm{MN}$ array consisting of drug or therapeutics dissolved or degraded into simulated fluid held with dermal microcirculation by crossing the barrier of $\mathrm{SC}$ via self-made microchannels, which allows the release of drug as per compendial requirements. However, they are only applicable to the drug with high potency which is delivered in low doses [32, 34]. The most recent addition to MN technology is hydrogel-forming MN arrays, which are fabricated from polymeric materials that have been cross-linked. The MN arrays pierce the SC and draw up interstitial fluids, leading to swelling of the polymeric matrix. Thus, the therapeutic agents enter to the dermal tissue by molecular diffusion through this swollen polymeric matrix. Hydrogel-forming MN arrays contain no active agent and, as such, instead, the active pharmaceutical ingredient can be loaded into an associated reservoir, viz., a polymeric film, directly compressed tablet/lyophilized reservoir due to which high amount of drug penetrates through the skin [37]. The employment of $\mathrm{MN}$ arrays recommended several improvements for estakamine (ESK) delivery that could be useful in TDDS. The proposed MNs transdermal delivery technology covers a narrative approach for facilitating the continuous delivery of ESK (with no pain) [38]. Surprisingly, notwithstanding the emergence of biotherapeutics and the merits furnished by hydrogel MNs, there has been very little research carried out to assess the capabilities of this delivery system to enhance the delivery of such molecules [37, 38].

\section{Other forms of MNs}

Fabricating the hydrogel-forming MNs is eye-catching to deliver the therapeutic as being more biocompatible with controllable degradation property. In addition, a smart or bio-responsive hydrogel can be intended to counter external environmental change. Bio-responsive MNs can be activated in reaction to biochemical stimuli like $\mathrm{pH}$, glucose, reactive oxygen species, and enzymes, to deliver protein therapies. Since various kinds of physiological circumstances, including differences in the MN matrix or incorporated carriers, may undergo dissociation or deterioration, it provides opportunities for precise ondemand payload release [39]. Nowadays, another type of MNs namely porous MNs is also high in demand. MN array receives gains with less prominence due to its complex, time-consuming, high-cost fabrication, and easy fracture in comparison with solid and hollow MNs [40]. Silicon, polymer, ceramic, and metal (Table 2) can be employed to fabricate porous $\mathrm{MN}$ array. Li et al. developed a porous polymeric $\mathrm{MN}$ array via photopolymerization of an acrylate monomer in the existence of a pyrogen within a mold for quick fluid convey. Yan et al. fabricated Ti porous MNs by an integrated method of wire-electrode cutting and wet etching from a porous $\mathrm{Ti}$ wafer for the insulin injection. This production method is expensive and not suitable for the mass production of porous MN array [40].

\section{Fabrication techniques of MNs}

A range of methods was explored to prepare unique MNs. In this section, we address the list of techniques to the specific variety of MNs. In this line, the selection of fabrication methods for MNs solely depends on the kind of MNs, the geometry of MNs, and the sort of material utilized. The various techniques applied for different types of MNs have been described below in Table 2 . 


\section{Characteristics of MNs}

In the precision of MNs, versatile pharmaceutical, cosmetics, and medical applications have drawn the attention from the last decade. In comparison to the other conventional drug delivery methods, MNs are at the forefront. Furthermore, the MNs have drawn more attention in pre-clinical and clinical trials for a safe and efficient product. Besides this, it shows significant growth due to the notable outcomes of the clinical trials. The MNs as an adaptable and efficient promising carrier for pharmaceutical applications have been widely reported. It may due to its versatile and tunable characteristics. In this shade of light, we have enlisted the characteristics of MNs and their specific required description [1-7] into Table 3.

\section{Characterization of MNs}

The active pharmaceutical ingredient is loaded on the MN surface or inside the MNs. The various drugcontaining formulation can be used for the loading of drugs which includes encapsulation form (example: liposomes, nanoliposomes, and NPs) and drug suspension or dispersion [41]. The active agent can use as a patch or coat into a polymeric solution. The characterization includes the size of particles, polydispersity index, zeta potential, and viscosity determination and that can be used for loaded drugs, which solely depend on the formulation employed in the invention of drug-loaded $\mathrm{MNs}$ [42]. The adhesion testing and permeation study were carried out for a patch-based approach that was normally used after pretreatment. The percent content, in vitro release evaluation has been performed for nearly many MNs. With nanocarriers, vesicle size, and internal

Table 3 Characteristics of MNs

\begin{tabular}{|c|c|c|}
\hline $\begin{array}{l}\text { Sr. } \\
\text { No. }\end{array}$ & Property of MNs & Description \\
\hline 1. & Ruggedness & $\begin{array}{l}\text { Should be able to resist the insertion force } \\
\text { without being featured. }\end{array}$ \\
\hline 2. & Penetration & $\begin{array}{l}\text { Must be penetrated the drug at the } \\
\text { required depth of tissue. }\end{array}$ \\
\hline 3. & Dimensions & $\begin{array}{l}\text { Length :- } 100-900 \text { microns; } \\
\text { Base width :50-300microns; } \\
\text { Tip diameter: 1-50microns }\end{array}$ \\
\hline 4. & Margin of safety & $=\frac{\text { the force required for piercing the } S C}{\text { the force at which MNs broke }}$ \\
\hline 5. & $\begin{array}{l}\text { Effect of the MN } \\
\text { length on pain }\end{array}$ & $\begin{array}{l}\text { As the length of the needle increases from } \\
\text { (i.e., } 500-1500 \mu \mathrm{m}) \text {, the pain increases. Also, } \\
\text { an increase in the digit of MNs from } 5 \text { to } \\
50 \text { resulted in the increases in the pain. }\end{array}$ \\
\hline 6. & $\begin{array}{l}\text { Transepidermal } \\
\text { water loss }\end{array}$ & $\begin{array}{l}\text { Intact animal skin, sing diffusion cell as well } \\
\text { as probes that evaluate transepidermal } \\
\text { water loss before and after MN application }\end{array}$ \\
\hline 7. & $\begin{array}{l}\text { Biological safety } \\
\text { test }\end{array}$ & $\begin{array}{l}\text { Extract chemicals from MNs by immersing } \\
\text { them in physiological saline and apply } \\
\text { them on intact human skin. }\end{array}$ \\
\hline
\end{tabular}

structure analysis, crystallinity can be investigated. Moreover, the drug-containing dispersion can be tested for stability studies. The designed MNs also evaluated in biocompatibility studies. Besides the abovementioned characterization, MNs can also check at a different simulated condition such as $\mathrm{pH}$, temperature, and in vivo physiological conditions [12, 43, 44].

\section{Dimensions of MNs}

It includes needle geometry, mainly for $\mathrm{MN}$ tip radius, height, length evaluation, etc. as depicted in Fig. 2. The various (optical or electrical) methods or techniques have been explored for dimensional evaluation of MNs which includes scanning electron microscopy and confocal laser microscopy [12]. This technique can provide the geometry of the 3-dimensional needle, which is more beneficial to the quality control purpose. Scanning electron microscopy provides detailed information about the surface topography of MNs, and a confocal layer microscope can be utilized for high-resolution images of MNs $[45,46]$.

\section{Mechanical properties of MNs}

As per the requirement of $\mathrm{MN}$ criteria, MNs should be enough sharp, slender, and strong, which can provide sufficient penetration and can avoid the MNs breaking while driving them inside the selected part of the body $[12,47]$. The mechanical properties include insertion force, insertion depth, and failure force and which are investigated using unorthodox methods such as dye marking, force-displacement test, electrical measurements, histological cryosectioning, staining, confocal microscopy, and optical tomography [48, 49]. The ratio of insertion forces to the failure forces is normally called a safety factor and it should be high as possible. Normally, the $\mathrm{MN}$ integrity and insertion force depend on the forces used during application. It is the most prominent fact for the synthesis of proficient and harmless design of MNs [12, 48].

\section{In vitro testing of MNs}

The in vitro testing is conditioned to hit upon the permeation or active (drug) release from MNs into the selected dissolution media [47]. In vitro study of smart MNs is generally performed using the diffusion cell apparatus. The pig ear skin is preferred for evaluation of the permeation of active agent [12]. Besides this, the cumulative permeation profile is tested for both cases which include MN treated skin and untreated skin penetration and this compared permeation profile can be helpful for the progress of efficient MNs [50].

\section{In vivo testing of $\mathrm{MNs}$}

In vivo testing of MNs was performed for analysis of key objectives such as biosafety (safety and toxicity) and 


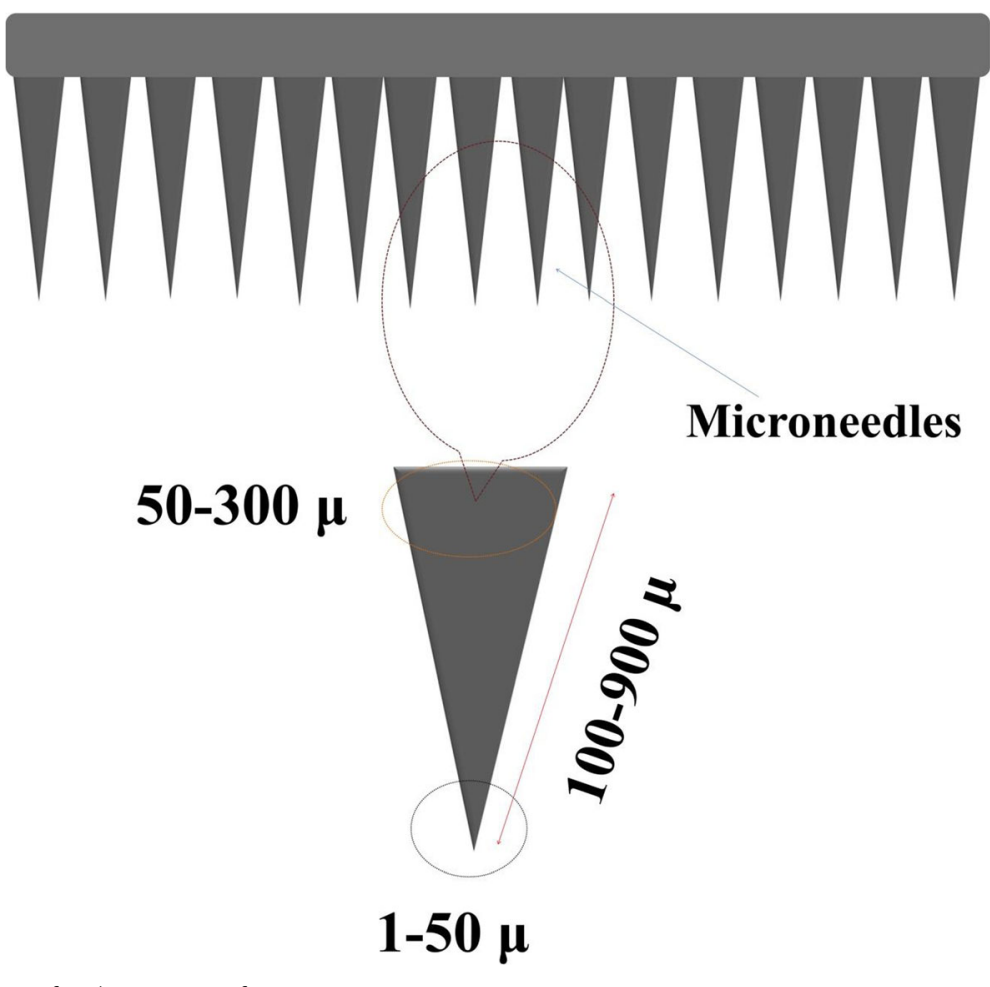

Fig. 2 Schematic representation for dimensions of MNs

in vivo pharmacokinetic and pharmacodynamic evaluation of the active pharmaceutical ingredient. Here, the hairless animal (for example mice/mouse, rabbits, guinea pigs, and monkeys) can be applied for the in vivo testing study [47]. In addition, we can evaluate the various parameters such as transepidermal water loss (TEWL), bioavailability, skin irritation, or inflammation. TEWL testing was performed before and after microneedling using the Delfin vapometer [50].

\section{Drug delivery methods}

A plentiful literature survey reported the delivery of active agent using MNs by the various method for the targeted/local site or regiospecific and systemic delivery [51]. Out of numerous sites, the delivery of active agent into the epidermis layer of skin and ophthalmic route, nail route, etc. has gained additional interest [52, 53]. For delivery of active agent, various methods have been reported which include direct transport pathway, wherein small holes are created on the application site using MNs, and then the drug-containing patch was placed in those holes. Another drug delivery approach is considered, viz., coating of MN surface by drug solution. Herein, the drug-loaded MNs are scrapped on the application site. Drug-loaded biodegradable MNs have been extensively applied for active delivery in the pharmaceutical field $[12,51]$. In transdermal drug/active delivery via MNs, the unique approaches can be used to deliver the active agent into the epidermis layer. One approach is to fill the drug solution into the hollow space of the synthesized hollow MNs. The next approach includes the incorporation of active agent into biodegradable polymers and further synthesized MNs using polymer and active mixtures. The next approach involves the dipping of the tip of MNs into the prepared active/drug solution and scrapes the MNs on the local area of skin, where drug/ active agent is left behind into the developed abrasions by needles $[12,14,54]$. Besides this, the surface of smart MNs was coated using a drug solution (coating solution); herein, the coated MNs are inserted into the selected local area where the drug is dissolved from the surface-coating layer on the needle. Another approach is to poke the selected area of the site with MNs to create the holes, and after successively creating a hole, the drug-loaded patch is applied over the holes, wherein the holes provide the direct path to the drug to deliver across the skin. Besides this, the electric field applied for an excellent outcome [1, 12, 47]. Many strategies have been explored to deliver the active agent to the ocular site and MNs (hollow, soluble, and coated) are one of them [53]. With this fact, majorly the ocular delivery of drugs has been reported using drug-loaded biodegradable (dissolvable) MNs, wherein the drug-containing hydrogel was prepared using suitable polymers and molded into the dissolvable MNs [55]. Meanwhile, the drug molecules were delivered by coating the drug on 
the surface of stainless steel MNs and MNs were delivered into the frontal segment of the eye [53]. Another study reported the delivery of the medicine by hollow glass MNs in the form of microparticles/NP formulations $[35,56]$. Chiu et al. have accomplished drug delivery through the nail. In this study, it delivered the active agent-loaded NPs via a nail. The NP formulation postapplication has been performed on an $\mathrm{MN}$-prorated nail [57]. Aksit and team reported the ultra-sharp full metallic MN-based active delivery tool for the inner ear. The design of MNs was based on gold-coated metallic MNs and can be potentially used for the release of the drug round window membrane with different drug delivery approaches [58].

\section{Pharmaceutical and biomedical applications of MNs}

Several pieces of research have been done on the utilization of MNs in different pharmaceutical and biomedical applications. MNs have been shown to have an outstanding drug release as well as have been used for several biomedical applications. MN-based platforms possess excellent drug/protein/peptide loading and targeted/controlled/sustained release ability as well as many additional applications that can be explored to develop the versatile platform for pharmaceutical and biomedical applications. Apart from transdermal drug/ protein delivery, these MNs have been reported to be an excellent carrier for an alternative strategy for drug delivery through nail, nasal, ocular, and ear. The various pharmaceutical and biomedical applications of MNs have been discussed in detail to get an insight into the potential of these MNs in several safe and effective human applications (Fig. 3).

\section{Applicability of MNs through transdermal route}

Owing to the drawbacks of the oral and conventional route of administration the transdermal route has been widely accepted, due to imperative characteristics that help to reach required plasma concentration at the target site for a prolonged period [59]. Thus, MNs are considered as a more promising tool for TDDS as microchannels created by them allow the easy and painless delivery of therapeutics as compared to that of hypodermic needles [60]. For enhancing the therapeutic

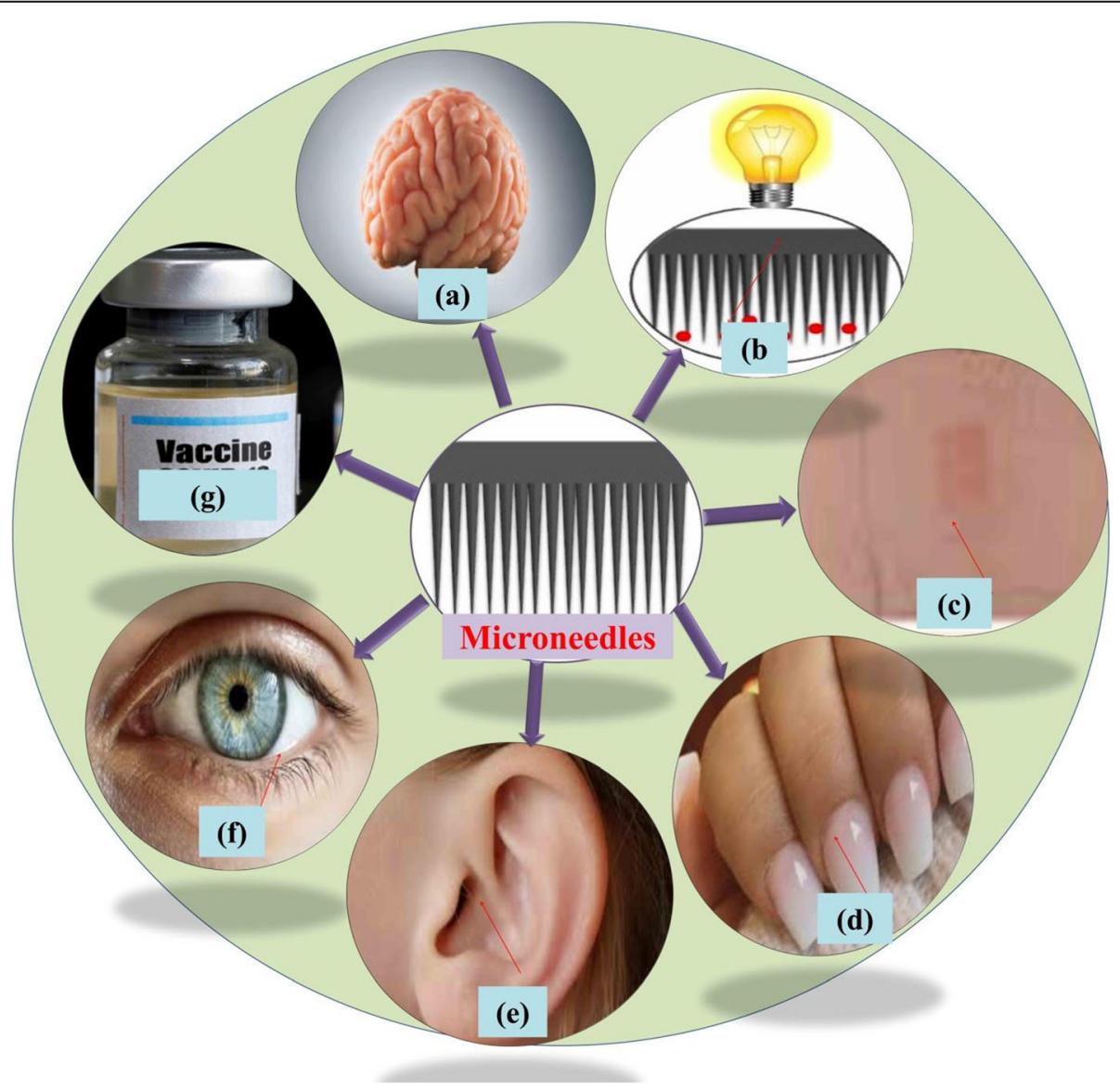

Fig. 3 Pharmaceutical and biomedical applications of MNs. a MNs for drug delivery to the brain. $\mathbf{b}$ MNs as a sensor. c Applicability of MNs through transdermal route. $\mathbf{d}$ MN drug delivery to nails. e MN drug delivery to the ear. $\mathbf{f}$ MNs for ocular delivery. $\mathbf{g}$ MNs for vaccine delivery 
efficacy of therapeutics by transdermal delivery, various kinds of MN formulations are used [61]. Wu et al. fabricated sumatriptan succinate (SS)-loaded MN arrays from sodium hyaluronate to enhance their therapeutic efficacy for transdermal delivery. The in vitro experiment demonstrated came with finding that the microchannels created by MNs immediately healed the skin damage and it was reversible. The study also evinced that the desired plasma concentration of drug was obtained by delivery through SS-MNs in rats with equivalent absorption to that observed after subcutaneous injection with high bioavailability (90\%), which is greater in comparison with oral administration [62]. The literature survey evinced that the partial studies have been performed for the delivery of several therapeutics like a poorly soluble drug, antibacterial drug, and antiretroviral drug-using liposomes, ethosomes, cubosomes, and microemulsion. The poor stability, high cost, and complex technique limit the application of these nano-vesicular systems on a large scale, while microemulsion applications are not considered as a suitable approach for the long-term delivery of therapeutics. Therefore, an original approach in which drug-loaded NPs were accomplished with MN insertion was utilized for the delivery of drugs especially with small molecular weight and drugs having short half-life to enhance the stability of formulation [63]. Ramadan et al. developed polymeric lamivudine (LAM)loaded NPs for transdermal delivery via passive diffusion and $\mathrm{MN}$-mediated transport then further investigated for long-term stability and penetration enhancement. The studies revealed that this delivery could be enhanced notably by MN pretreatment of skin with longterm stability [64].

The plentiful literature revealed that the MNs used for transdermal delivery have many advantages, even though these MN-based drug delivery is a passive manner regardless of the changing physiological circumstances of patients. It is often difficult to completely avoid the toxicity caused by overdose or the inefficacy attributable to underdosing [65]. Thus, to overcome this mentioned limitation, transdermal delivery is decorated with the advanced bio-responsive method which is specifically used to treat the different kinds of diseases like diabetes and cancer. Diabetes mellitus is a challenging global disease around the world. The disease is caused by increasing blood sugar level either due to low-level secretion of insulin or less cellular uptake of secreted insulin within the body. Thus, various approaches have been explored for daily insulin administration, e.g., oral, nasal, pulmonary, and transdermal [66]. Literature survey unveiled that insulin delivered through the skin does not suffer from a scarcity of chemical and enzymatic degradation concerns. Furthermore, its convenient nature may considerably increase patient adherence [67]. Currently, subcutaneous self-injection is considered a widespread method for insulin administration. Nevertheless, this process is painful and inconvenient, reduces patient compliance, and also leads to microbial contamination, local tissue necrosis, and nerve damage [68]. Hence to overcome aforesaid limitation, an artificial pancreas-like, closed-loop, glucose-responsive insulin transport system that can "secrete" insulin in response against elevated blood glucose would provide a desirable way of regulating glycemia with minimal patient effort and potential improvements in glycemia and quality of life [69]. However, several challenges are related to such unique devices for example guaranteeing precise signal feedback and avoiding biofouling [70]. Yu et al. reported a glucose-responsive insulin delivery device by using a painless MN patch coined as a "smart insulin patch" that contains glucose-responsive insulin and glucose oxidase (GOx)-loaded vesicles. This smart and new insulin MN patch successfully regulated blood glucose of chemically induced diabetes type 1 in the mouse model. The sooner responsiveness of this method holds great promise in avoiding hyperglycemia and hypoglycemia if translated for human therapy [71]. Chen et al. investigated a smart MN based on semi-interpenetrating network (semi-IPN) hydrogel that was prepared using SF and phenylboronic acid/acrylamide for exceptional glucose-responsive insulin delivery. The hybrid MNs originally released insulin well similar to the glucose alteration pattern and suggesting the possibility for sustained delivery [39]. In 2018, Liu et al. prepared MN-based near-infrared (NIR) responsive photothermal therapy (PTT) for diabetic care as an attractive alternative to combine with chemotherapy and it could serve as a promising platform for delivering other therapeutic drugs via transdermal delivery [72]. Yu et al. have developed the MNs of alginate and hyaluronate for transdermal delivery of insulin. In brief, MN $(650 \mu \mathrm{m})$ patches are made with alginate and hyaluronate loaded with insulin. It showed admirable pharmacologic availability (90.5\%) and relative bioavailability (92.9\%) of insulin from MNs in mice [73]. Kolli et al. divulged the upshot of iontophoresis and MNs for TDDS of methotrexate (MTX). The synergistic effect was found due to iontophoresis and MNs. It has been showing a 25-fold enhancement of delivery in vivo in combination (MNs-iontophoresis), compared to each one alone [31]. Gomaa et al. reported the laserengineered dissolving MNs to nadroparin calcium to the transdermal delivery. The fabrication of laser-engineered dissolving $\mathrm{MN}$ arrays was fabricated by poly(methylvinylether-co-maleic anhydride) with nadroparin calcium. The MNs offer immense potential as a relatively lowcost functional delivery system [74]. In 2008, Wermeling et al. have claimed for TDDS of naltrexone using MNs to the skin in medication to humans. Briefly, a clinical 
study confirmed the MNs for enhanced naltrexone delivery in a transdermal patch [75].

For TDDS of functional therapeutics, MNs have been extensively used in a noninvasive manner. However, launching an easy and widespread way to assure balanced filling of a large number of drugs is still imperative especially for nucleic acid-based drug delivery. To discourse the issue, universally applicable ribonucleic acid (RNA)-based transdermal delivery was endorsed to manufacture purpose-oriented MNs [76]. Although the hypodermic needles used efficiently deliver siRNA via $\mathrm{SC}$, the main issue is that this method is painful. Thus, MNs may signify a superior way to distribute siRNAs across the SC [77]. Currently, methods like cavitational ultrasound, electroporation, iontophoresis, or intradermal injection have been used to overcome the barriers using cell-penetrating peptides [78]. However, the first three methods are complicated, time-consuming, expensive, and not so "patient-friendly." Thus, overcoming the aforesaid limitation delivery of siRNA into the skin by MN devices was investigated [78]. Dang et al. first time evaluated silicon solid $\mathrm{MN}$ array for cholesterol delivery with advanced housekeeping gene (Gapdh) siRNA to the skin (in vivo) (Fig. 4). The study evinced MN use to deliver the siRNA, which should generate little or no pain. Thus, the application of $\mathrm{MN}$ array could effectively transit the SC, deposit siRNA into the epidermis, and silence the Gapdh gene [80]. Wang and colleagues developed NP-powered MN patches of siRNA that contain a dissolvable HA. The study performed revealed that once a transdermal patch was inserted into the skin, the HA matrix dissolves, and $\mathrm{mSiO}_{2}$-coated upconversion NPs (UCNPs@ $\mathrm{mSiO}_{2}$ ) diffuse in the skin tissue before entering the cells for delivering the loaded genes. Thus, as a proof of concept, this system is used to deliver the molecular beacons (MBs) and siRNA comprising targeting transforming growth factor- $\beta$ type-I receptor (TGF $\beta$ ) matrix and UCNPs@mSiO 2 potentially used for scar treatment [79].

In the last years, protein and protein-peptide-based therapeutics gain vital importance for the development of the new drug; however, this process suffers from a lot of difficulties and obstacles as peptides face hurdles like instability under high temperature, light, and high/low pHs, and digestion by gastrointestinal enzymes during oral delivery [81]. MNs hold the potential to avoid oral uptakes, considered an effective tool for protein and peptide. Coating the needles with protein-based therapeutics is the simplest method for the invention of the same. However, optimization and adjusting by suitable excipients is a prominent requirement of coating formulations to achieve a uniform and sufficient coating [28]. Preloading drugs into the needles during the fabrication is an alternative way [82]. Liu et al. reported peptide delivery with poly(ethylene glycol) diacrylate (PEGDA) MNs through swelling effect. Herein, they introduced the loading of PEGDA-MNs with peptides. The peptideloaded MNs were successfully applied to a keloid scar model, which showed inhibition expression of collagen I (a predominant marker of a keloid scar), therefore showing its potential therapeutic effects [83]. Chen et al. investigated $\mathrm{MNs}$ for a smart and new exendin-4 (Ex4) delivery along with dual mineralized particles that separately contain active agents namely Ex4 and GOx. The study evinced that the incorporation of mineralized particles can improve the mechanical strength of alginateMNs via cross-linking to make easy skin penetration [84]. Zhang and co-authors reported the hydrophilic peptides in vitro delivery through transdermal MN array pretreatment. In this way, it improved genetic immunization by way of micromechanical disruption of the skin [85].

Over the decades, hypodermic needles were conventionally used for vaccination due to their rapid and direct delivery of the vaccine. Despite the familiarity, universal use, and proven efficacy of the hypodermic needle accompanying unintentional needle stick injury, the spread of blood-borne infections as well as phobias, pain, and significant anxiety is still present [86]. Besides, unless an individual gained specialized training to become an expert in injection technique and needle disposal, they are not easy to use through selfadministration. To overcome these limitations, vaccination through the oral route is considered an acceptable alternative. However, this mode of immunization is less effective, as vaccine antigens undergo gastrointestinal digestion before the induction of an adequate immune response [87]. Vaccination through a diffusion-based transdermal route has also been investigated. However, it allows the prevention of vaccines to pass through different skin layers due to the outer SC layer. Charles Mantoux (French physician) investigated (1910) the first tuberculin intradermal injection as a diagnostic purpose for tuberculosis disease [88]. However, vaccination through intradermal injection is considered more challenging and required trained or expertise operators for their use and been associated with adverse events such as pain, inflammatory changes, and the development of abscesses. Thus, taking into consideration the limitations of parenteral, oral, and traditional transdermal, and intradermal vaccination, the concept of the MNs emerged as a solution to these issues [89]. Shin et al. developed cyclic diguanylate monophosphate (C-di-GMP) with the influenza vaccine, which showed improved and shifted immune reactions in $\mathrm{MN}$ vaccination in the skin. They also demonstrated the applicability, immunogenicity, and protective efficacy of c-di-GMP. Thus, this study proved that GMP is an efficient adjuvant for 


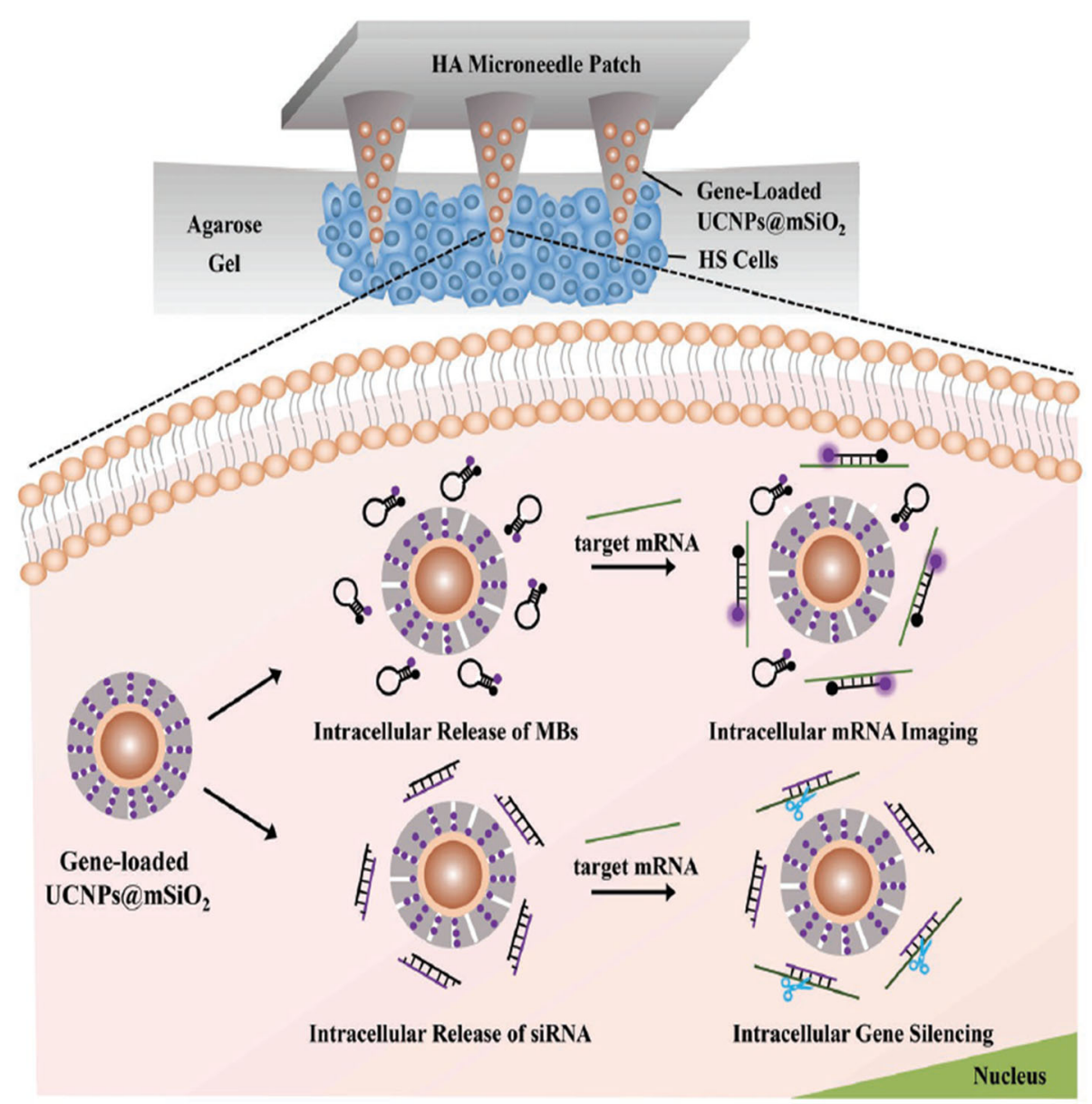

Fig. 4 Transdermal application of HA-MNs powered with UCNPs@mSiO2 containing mRNA MBs and siRNA for gene monitoring and gene silencing in 3D gels (taken with permission from [79]. Copyright@ 2019 Wiley-VCH Verlag GmbH \& Co. KGaA, Weinheim)

influenza MN vaccination [90]. In 2018, Duong et al. demonstrated that the MNs along with charge reversal pH-sensitive copolymers perk up antigen-presenting cells-homing DNA vaccine delivery and immune responses. In vivo demonstrated DNA delivery of a vaccine encoding $A \beta$ fusion protein to antigen present cells induced a robust antigen-specific immune response [91]. Zhu et al. 2017, reported the boosting skin vaccination is accomplished by dissolving $\mathrm{MN}$ patch encapsulating the extracellular domain $\left(\mathrm{M}_{2} \mathrm{e}\right)$. The results of these studies evidenced receiving recombinant flagellin (tFliC). MNs (4M2e-tFliC) of carboxymethyl cellulose (CMC) boost immunization of the array which has $100 \mathrm{MNs}$ (250 and $650 \mu \mathrm{m}$, diameter and length, respectively [92]. In 2015, Hirobe et al. reported the clinical study of transcutaneous influenza vaccination using a dissolving MN patch. In that, the MNs of HA with hemagglutinins of influenza for vaccination induce a strong immune response [93]. Edens et al. showed the MN patch containing the measles vaccine is immunogenic in non-human primates. Herein, vaccination with MNs was loaded with an antibody of measles that was immunogenic in nonhuman primates [94]. Hiraishi et al. divulged the Bacillus Calmette-Guérin (BCG) vaccination using a MN patch. Herein, the vaccination patch was coupled with MNs, preloaded with BCG for the treatment and prevention of tuberculosis [95]. Coated MNs for transcutaneous delivery of live virus vaccines were studied by Vrdoljak et al. Silicon MNs were coated using a spray containing adenovirus antigen and virus Ankara that stimulated CD8 cells of the immune system [96].

Sustained and controlled delivery of drugs can be achieved by encapsulating drugs in biodegradable or synthetic polymer, and it increasingly becomes the trend of MN technology. To achieve release of incorporated therapeutics as per compendial requirements, the matrix of biodegradable MNs often chosen is made from polymers like chitosan (CS), PLA, polyglycolic acid, or poly(lactide-co-glycolide) [97]. Gao et al. reported novel polydimethyl siloxane (PDMS)-based negative mold with cavities packed with SF scaffold for rapid fabrication of polymeric MNs, which comprise primarily the 
composition of PEGDA and sucrose as the needle matrix. Briefly, rhodamine (RhB), doxorubicin (DOX), and indocyanine green (ICG) were selected as a model drug. The prepared PEGDA/sucrose MNs were evaluated for effective transdermal delivery and controllable release of therapeutic molecules by regulating the sucrose content. The experimental evidence has proven that the presented method provides a simple strategy for quick fabrication of polymeric MNs toward transdermal and controlled drug delivery applications [98]. Additionally, He et al. reported intradermal implantable polylactic glycolic acid (PLGA) MNs for etonogestrel (ENG). They designed the implantable MN array via a controllable casting-mold method that allows ENG sustained intradermal delivery [99]. A literature survey revealed that the MN system is used for transmission of drugs, proteins, genes, RNA, vaccines, and other biological macromolecules, and they are highly efficient, convenient, and harmless [100].

Recently, the MN-based TDDS has provided a broad application prospect for skin cancer [101]. Tham et al. demonstrated a mesoporous nano vehicle with dual loading of photosensitizers and clinically relevant drugs to facilitate their penetration into the deep skin tissue. The developed mesopores of the NPs were further loaded with dabrafenib and trametinib (small-molecule inhibitors). The experimental data obtained from the present study evinced that the prepared nano vehicle could significantly inhibit the proliferation of tumor cells in a 3D spheroid model in vitro. Porcine skin fluorescence imaging demonstrated that MNs could facilitate the penetration of nano vehicles across the epidermis layer of skin to reach deep-seated melanoma sites. Tumor regression studies in a xeno-grafted melanoma mouse model confirmed superior therapeutic efficacy of the nano vehicles through combinational PDT and targeted therapy [102]. Hao et al. reported a NIR lightresponsive 5-fluorouracil (5-Fu) and ICG-based monomethoxy-poly (ethylene glycol) polycaprolactone (MPEG-PCL-NPs) (i.e., 5-Fu-ICG-MPEG-PCL). Then 5Fu-ICG-MPEG-PCL was integrated with an HA-MNs to get 5-Fu-ICG-MPEG-PCL-loaded HA-MNs for treating skin cancers, including human epidermoid cancer and melanoma. They investigated that 5-Fu-ICG-MPEG-PCL composite could be delivered through the smart and dissolvable MNs throughout the skin. The release performance of the active ingredient in the developed NPs could be controlled by NIR light for accomplishing a singledose treatment of skin cancer, progress in a cure rate of cancer, and offering a new proposal and prospect for the clinical management of skin cancer [103].

Transdermal administration is a favored route of administration due to its advantages mentioned earlier [104]. SC barrier noticeably limits the larger molecules (proteins and therapeutic genes) transdermal delivery. To enhance the SC permeability, several techniques, viz., ultrasound, electroporation, iontophoresis, microdermabrasion, and thermal ablation, have been developed. However, the majority of these techniques failed to owe to the possibility of skin irritation that is intolerable in a clinical setting [105]. To overcome the challenges subjected, previously mentioned MNs arrays gain significant interest in both TDDS and transdermal diagnostics. Vora et al. reported pullulan (PL)-based dissolving MN arrays for enhanced TDDS of small and large biomolecules. They reported for the first time, the preparation and characterization of a dissolving $\mathrm{MN}$ system from the carbohydrate biopolymer, PL. Model molecules and protein/peptide were loaded into PL-dissolving-MNs and characterized. The stability of fluorescein isothiocyanatelabeled bovine serum albumin (FITC-BSA) and insulin (model biomolecules) following dissolving MN manufacture was assessed via circular dichroism (CD). This study showed that PL-dissolving-MNs show to be a potential tool for efficient transdermal delivery of small as well as large molecules [106].

\section{MNs for ocular delivery}

Several peoples from the universe have been suffering from the loss of vision due to age-related ocular diseases [107]. Auspiciously, great expansions of the latest tactics were accepted for ocular drug delivery, including biologics [108]. Up to date, various kinds of approaches have been established, such as systemic, topical, periocular (or transscleral), and intravitreal routes that have been adopted. Ocular delivery of drug topical (e.g., through eye drops) and systemic (e.g., oral tablets) routes could not achieve the required therapeutic concentration of drug due to multiple ocular barriers, a high amount of dose is needed to administer leading to scarcity requiring administration of unnecessarily drugrelated toxicity and producing low treatment efficacy [109]. To overcome the ocular barrier function and to enhance the localization of the drug close to the target tissues, intravitreal, intracorneal, and intrascleral injections were investigated [110]. However, this method does not gain the required bioavailability of therapeutics due to delay in the diffusion in the ophthalmic cavity. Besides, the use of traditional injection frequently over a prolonged period can put forth several complications and poor patient compliance indicates the need for lessinvasive technologies that will enhance patient compliance and allow localized, precise drug delivery to the eye [111]. Thus, considering the facts of care, the application of minimally invasive MNs for ocular active delivery is a relatively new concept. Singh et al. developed rapidly dissolving polymeric MNs for minimally invasive intraocular drug delivery. MNs were fabricated using PVP 
polymer of various molecular weights namely fluorescein, sodium, and fluorescein isothiocyanate-dextrans (MW of $70 \mathrm{kDa}$ and $150 \mathrm{kDa}$ ). These MNs showed a quick dissolution rate, and in vitro testing of $\mathrm{MNs}$ showed noteworthy improvement of macromolecule permeation. Furthermore, the confocal images demonstrated that the macromolecules created depots within the tissues that guide to sustained permeation rate [55]. Than et al. reported self-implantable double-layered microdrug reservoirs for efficient and controlled ocular drug delivery. These MNs can be implanted as micro reservoirs for controlled drug delivery with enhanced therapeutic efficacy. The study evinced the antiangiogenic monoclonal antibody (DC101) delivery via such eye patch generates a $\sim 90 \%$ reduction of the neovascular area with synergistic therapeutic outcome [112]. In 2016, Khandan and co-authors have been fenestrated MNs for ocular active pharmaceutical delivery. The capability of MNs can be up to 5-fold relative to solid MNs [113]. Furthermore, Kim and colleagues reported MNs for site-specific antiglaucoma drug delivery to the supraciliary space [114].

\section{MNs for drug delivery to the brain}

The blood-brain barrier (BBB) which is considered as a tight connection made up from connecting the blood capillaries comprising endothelial cell with the tight junction of pericytes, astrocytes, and basal membrane [115]. Being hardest to cross, the major barrier, i.e., BBB, provides several limitations such as insufficient delivery of the therapeutic agent. Therefore, the number of central nervous system disorder remains untreated or difficult to treat. Moreover, the restriction imposed on the infiltration of the drug molecules' brain barrier allows the entry of only a small molecule having a molecular weight (especially less than $400 \mathrm{Da}$ ) or for the lipid-soluble drug [116]. Thus, the scenario created the necessity to develop techniques for crossing the BBB. Several advances have been made to explore the properties of $\mathrm{BBB}$ for the effective treatment of brain diseases, like the delivery of drug-using nanocarrier or NPs as noninvasive techniques to enhance brain drug uptake. In the past few decades, syringe injection has been used for the delivery of drugs to the brain. But these approaches are entitled with smoke limitations like serious issues regarding the probability of infection and inflammation at the site of injection together with the occurrence of pain and anxiety, which has drawn attention toward some alternative mode of drug delivery and incompetency toward the patient [117]. Kearney et al. investigated the donepezil hydrochloride (Alzheimer's drug)-loaded MN patch. In brief, MNs are made up of PVP or poly(methyl vinyl ether co-maleic anhydride/acid) polymers. Furthermore, in vitro permeation of donepezil hydrochloride across neonatal porcine skin from the patches was investigated, with $854.71 \mathrm{lg} \pm 122.71 \mathrm{lg}$ donepezil hydrochloride delivered after $24 \mathrm{~h}$, using patch formulation, signifying the accomplishment of this delivery proposal for donepezil hydrochloride to take care of brain disorder [118]. Another study reported that the silicon-based MNs for drug delivery in the deep brain. In this regard, MN array fabricated on silicon intended for infusion of activity in the brain to recognize connections as well as neuronal activities [119].

\section{MNs as a sensor}

Current therapeutic drug monitoring approaches rely on discrete blood measurements, being invasive, and limit the temporal resolution of the information obtained. Moreover, they are labor-intensive and not practical in a clinical environment. There is an immediate necessity for a minimally invasive approach for therapeutic drug monitoring [120]. There is a quickly rising interest in the use of transdermal MN-based electrodes in favor of molecular-based biosensing and drug delivery [121]. Examples of MN-based biosensors have been revealed for continuous screening of metabolic markers such as glucose and lactate as well as for the drug theophylline and organophosphate nerve agents [122]. These sensors only penetrate the $\mathrm{SC}$ and therefore do not cause pain or draw blood, as they do not reach the nerve endings as well as capillary blood vessels in the dermis. As a result, such sensors provide a minimally invasive means of sampling the interstitial fluids for drug or metabolite monitoring [123]. Gowers et al. developed a minimally invasive $\mathrm{MN}$-based sensor for constant monitoring of $\beta$ lactam antibiotic concentrations in vivo. The biosensor is coated with a $\mathrm{pH}$-sensitive iridium oxide layer, which detects changes in local $\mathrm{pH}$ because of $\beta$-lactam hydrolysis by $\beta$-lactamase immobilized on the electrode surface. These biosensors were found to be stable up to 2 weeks at $-20^{\circ} \mathrm{C}$ and to withstand sterilization. Sensitivity was retained after application for $6 \mathrm{~h}$ in vivo. These preliminary results showed the potential of this MN-based biosensor to provide a minimally invasive means to measure real-time $\beta$-lactam concentrations in vivo, representing an important first step toward a closedloop therapeutic drug monitoring system [124]. Wang et al. divulged the MN electrode array on a flexible substrate for long-term EEG monitoring. The utilization of MNs (silicone height of $190 \mu \mathrm{m}$ ) has been used that could be capable of electrocardiograph (EEG) monitoring. MNs can be adapted to the skin providing robust contact with skin [125]. The MN array electrodes for continuous glucose monitoring sensors are reported by Sharma et al. The use of MNs eliminates this interference to detect glucose in comparison with other devices' glucose [126]. The nitrogen-incorporated ultra 
nanocrystalline diamond MN arrays intended for electrochemical biosensing are demonstrated by Skoog et al. The nitrogen-incorporated ultra-crystalline diamondcoated titanium alloy $\mathrm{MN}$ arrays can sense electrochemical signals (dopamine and uric acid) [127]. The MN biosensor is meant for real-time electrical recognition. Owing to this in situ cancer, Keum et al. have accomplished biosensing using $\mathrm{MN}$ array. This system can use a new platform for the detection of cancer [128].

\section{MNs for cosmetics applications}

Considering the capability of the MNs to act more efficiently by application to the skin surface, they are widely considered to treat different skin disorders like seborrheic keratosis, scars, striae, anti-aging, wrinkles, or depigmentation. "Dermaroller" is the best example of $\mathrm{MN}$ based instrument. Tranexamic acid (TXA) is not only used for the treatment of post-acne but also in antiaging therapy with no sequelae. Machekposhti et al. generated MNs of PVP and methacrylic acid loaded with TXA. These MNs had adequate properties to be used to the skin and have a release in the TXA with the possibility of being an alternative for the management of melasma [129]. Another case of pigmentation is seborrheic keratosis or senile lentigo normally seen in people $>50$ years of age; the treatment is with all-trans retinoic acid (ATRA). Hibrobe et al. developed an ATRA-loaded microneedle patch (ATRA-MNs) to enhance the permeability of ATRA and microneedle patch loaded with retinoic acid. ATRA-MNs were applied on the lesion site of each subject once per week for up to 4 weeks (Fig. 5). This study has proven that MNs are promising as a safe and effective therapy for seborrheic keratosis and senile lentigo [130].

In this study, skin needling is a treatment for acne scarring and management of hypertrophic scar after burn wounds using MNs reported by Doddaballapur [131]. Seo et al. divulged the skin rejuvenation by MN

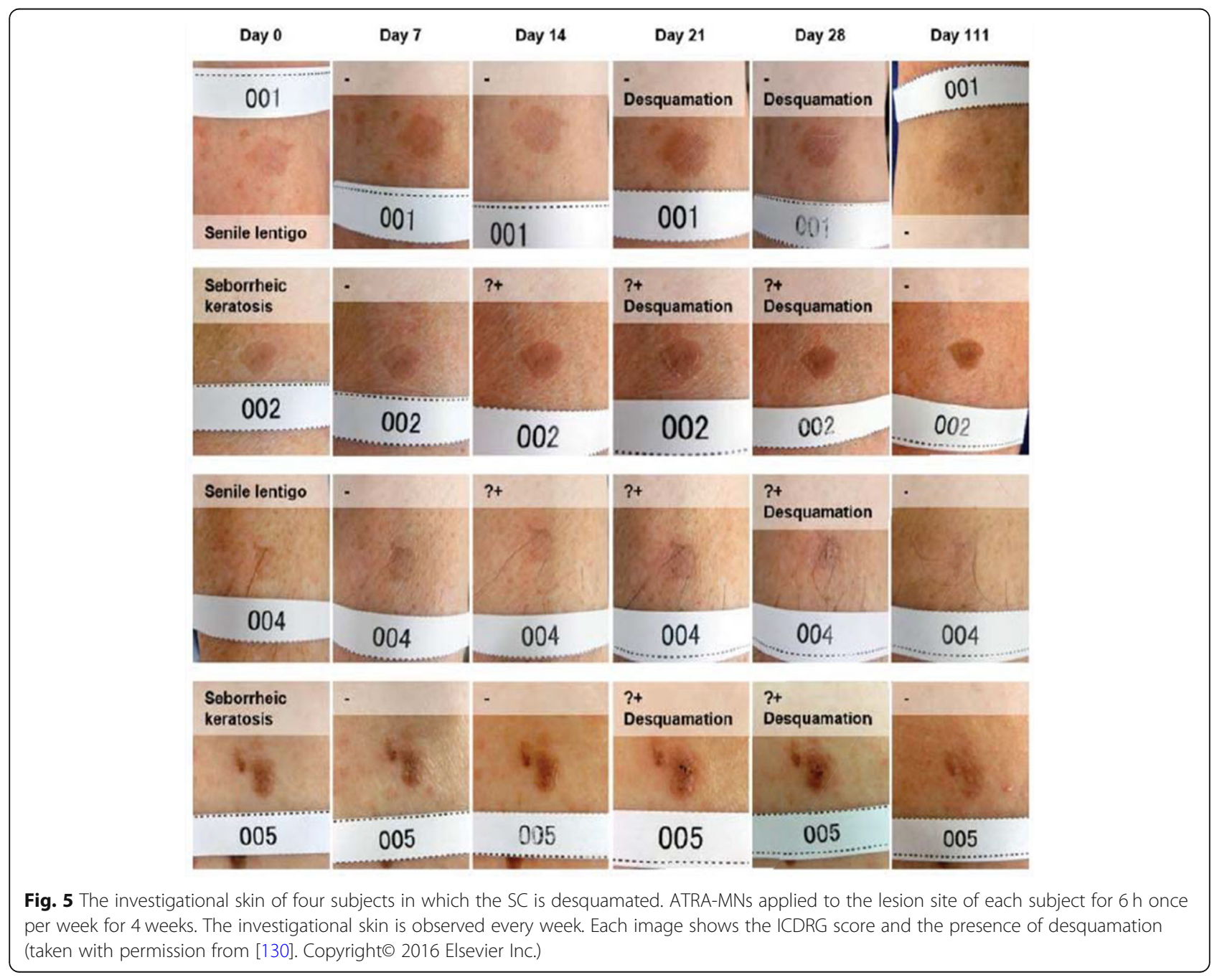


fractional RF and a human stem cell-conditioned medium. Fractional RF was used with MNs in the skin using stem cells for skin rejuvenation. The therapy with percutaneous collagen offers a modality with which to rejuvenate [132]. Triamcinolone acetonide-loaded MNs for alopecia areata have been claimed by Chandrashekar et al. [133]. Application of corticosteroids using MNs resulted in promoting blood supply to hair follicles for the alopecia areata treatment $[133,134]$.

\section{Miscellaneous application of MNs (delivery of the drug to ear, nails)}

From its inception, drug/active delivery into the cochlea (a fluid-filled cavity within the temporal bone of the skull) is a long-standing issue and yet crucial to treat various hearing disorders, viz., sudden or progressive sensorineural hearing loss and tinnitus and vestibular disorders (Meniere's disease). In this shade, it is well known that the inaccessibility as a fluid-filled cavity within the temporal bone of the skull is a major challenge to the researcher for the development of active delivery into the inner ear. Instead of this, the round window membrane (RWM) is the only active delivery portal from the middle ear to the inner ear that does not require perforation of bone. The plentiful literature revealed that $M N$ fabrication enables the RWM to be perforated safely with polymeric $\mathrm{MNs}$ as a means to enhance the rate of drug delivery from the middle to the inner ear. Unfortunately, the polymeric materials are not admirable and biocompatible and lack the strength of other materials. In 2020, Aksit and co-authors have designed and developed the gold-coated metallic MNs that are appropriate for RWM perforation using two-photon template electrodeposition fabrication technology. It accomplished the negligible degree of trauma in a guinea pig RWM. In addition, MNs themselves remain undamaged during inducing a perforation. Therefore, these innovative MNs open the RWM for enhanced active delivery into the inner ear for therapy of a range of ear diseases and disorders [58]. The conventionally engaged topical nail drug delivery system has a certain major limitation. It includes evaporation of the volatile solvent and low diffusivity of active ingredient across the nail plate due to its compact keratinized structure. In this regard, there is an urgent necessity to develop an advanced approach for the management of several nail diseases, for example, nail psoriasis and onychomycosis. Chiu et al. divulged the polymeric NPs as a suitable drug reservoir for topical (sustained) drug delivery into MNtreated human nails. Herein, dorsal side microporation of hydrated human fingernail clippings (at least $8 \mathrm{~mm}$ in length) has been achieved using commercially available dermaroller ( $250 \mu \mathrm{m}$ long titanium needles) via rolling it back and forth (5 times). The star-shaped PCL with 5,10, 15,20-tetrakis-(4-aminophenyl)porphyrin (TAPP) was synthesized using TAPP, stannous octoate $(0.0025$ $\mathrm{mmol}$ ), and $€$-caprolactone. Besides this, Nile red (NR) (lipophilic fluorophore)-loaded PCL-NPs were prepared by the solvent displacement method. In vitro nail permeation NR has been performed using vertical Franz diffusion cells. The results offer clear confirmation that NPs can function as reservoirs for NR (lipophilic compounds) and sustain their local release for several days. Therefore, the MNs in nail drug delivery are paving the substitute for the management of major health issues in biomedical and pharmaceutical fields [57].

All drugs designed to be used in vivo should require excellent pharmacokinetic parameters, i.e., proper and good absorption, delivery to the specific site, access to the target site, should attempt required circulation time in blood, and half-life clearance [135]. The drug, which attains these properties, is considered to be practically safe for use. Pharmacological and toxicological characteristics in any pharmaceutical product must be identified. The in vivo kinetics, bio-distribution, and absorption relationship helps in designing the MNs in various applications [136]. Incorporating the drug or its particles into dissolving MNs can significantly enhance its dermato-kinetic profiles, compared to conventional dosage forms (Fig. 6a) [137].

The pharmacokinetics and bio-distribution rely on its physicochemical characteristics including length, shape, aggregation, surface modifications, chemical composition, and permeation which can be enhanced by developing the functionalized MNs [138]. For the drug to become effectively bio-available, the drug-loaded (functionalized) MNs or arrays should be capable of prominent absorption from the site of administration. Drugs absorbed from the site of absorption are carried forward to the specific site of action through the blood or lymphatic system.

\section{In vivo and in vitro toxicity of MNs on an original model}

The major concern with MN-based applications is skin irritation, skin allergy, and redness. If the skin pore does not close after the MN patch application, it can develop a skin infection,[12, 21]. Much research has been carried out to test the MNs in vivo and in vitro toxicity by using different animals (mice/rat) and cell lines to observe whether the MNs are associated with perceived undesirable human health effects $[12,96,139]$. Table 4 shows the current updates on the toxicity studies of MNs performed.

\section{Recent MN patent as a drug delivery system}

From the last decades, MNs are most widely studied as delivery carriers. In this light, the researcher pays much attention to explore and improve the $\mathrm{MN}$ material and 


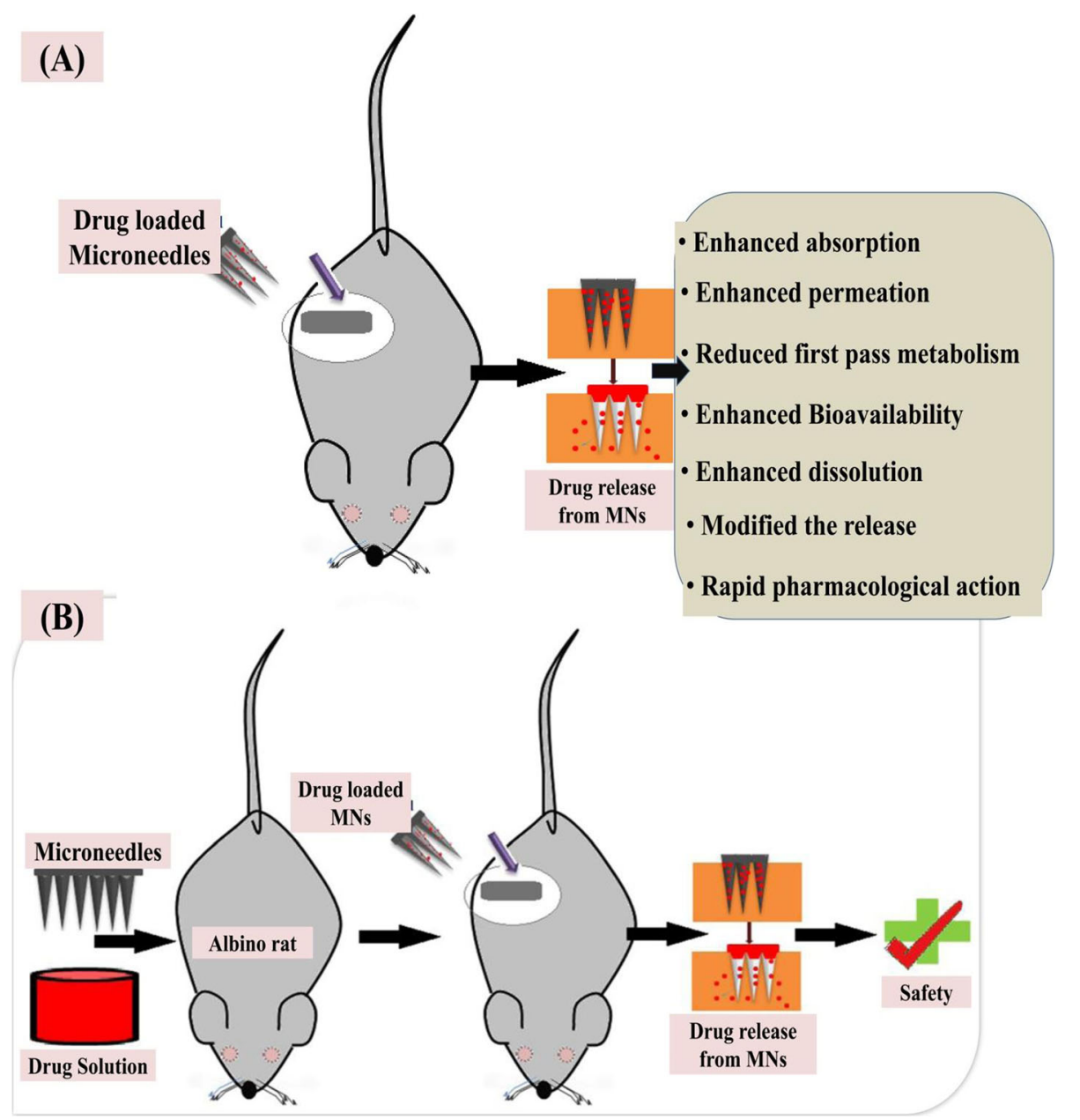

Fig. 6 a Applications of MNs enhanced the pharmacokinetic parameters. $\mathbf{b}$ Biosafety of MNs

its properties. In this way, it can be efficiently utilized for effective drug delivery along with low toxicity. There are various patents related to MNs including fabrication methods and drug delivery. The innovative strategy for targeted /systemic delivery of active agent using MNs has resulted in the number of patents as summarized in Table 5.

\section{Clinical trials on MNs}

The MNs are potential targeted and systemic drug delivery systems. With this, we can load the numerous kinds of drugs in MNs to achieve efficient pharmacotherapeutics. It provides plentiful merits such as biocompatible, less or nontoxic, controlled release, self and safe administration, and minimally invasive device for effective drug delivery $[152,153]$. Owing to this, there is a recommendation to develop the MN-based advance dosage form. From the last decades, undoubtedly, continued growth has been found with new formulation and fabrication methodologies for MNs [152, 154]. And we witnessed that MNs have successfully applied for the administration of drugs, cosmetics, proteins, vaccines, and peptides [47]. Out of this, the various products have been successfully availed clinically [12]. Despite the huge milestone, safety, and efficacy of MNs, the formulation is a major concern that has been raised. For human use, the MNs should shift to clinical trial and it is the key demand of government bodies of the respective country involved in the pharmaceutical and biomedical market [155]. The product was based on MNs developed by various industries to treat various health issues which showed exceptional safety and efficacy in clinical trial phase III [47, 155]. Besides, they completed successfully the list of product clinical trials and many more in the process [47]. Table 6 shows the example of completed clinical trials up to 2020 as per the ClinicalTrials.gov (resource provided by the U.S. National Library of Medicine). 
Table 4 In vivo and in vitro toxicity of MNs on a different model

Sr. Study Observation $\quad$ Toxicity effect $\quad$ Result/inference

No.

MNs free from in vivo and in vitro toxicity

1. The standard Draize skin irritation method was used to measure erythema and edema of the thiolated CS-MNs patch of tacrolimus.

2. A piece of rat dorsal skin was defrosted naturally, and then the curcumin micelle-loaded dissolvable composite MNs were inserted with the thumb using a force ( 5 N). Then MNs were removed after the insertion and the skin was exposed to trypan blue solution for $5 \mathrm{~min}$.

3. The hair on the back of each rat was shaved, and the aconitine loaded diethylene glycol monoethyl ether-mediated microemulsion assisted MNs was applied once daily for 7 consecutive days.

4. 5-Fu loaded monomethoxypoly(ethylene glycol)-polycaprolactone NPs integrated HA dissolvable MNs was evaluated for in vitro cytotoxicity by human epidermoid cancer cell line-A431 and the human melanoma cell lineA375 through MTT assay.

5. The gelatin methacryloyl and $\beta$ cyclodextrin (Gel-MA- $\beta$-CD) based MNs have penetrated the epidermal layer after $1 \mathrm{~h}$ of topical implantation.

6. In this study, two amifostinearmored MNs patches have been topically administered on the shaved dorsal skin (12 h).

7. Acute skin irritation of $3 \mathrm{~min}$ treatment by the MTX-HAdissolvable (MTX-HA) MNs was performed by using the dorsal skin of mice.

8. The cytotoxicity study of drug-free PEGDA/sucrose MNs was performed by human umbilical vein endothelial cells (HUEVCs) by MTT cell viability assay.

9. The study was carried out by applying MNs (without drug) followed by NIR light irradiation.

10. The Ex4 tip-loaded MN arrays and subcutaneous injections were compared for their acute efficacy in type 2 diabetic GK/Slc rats.

11. The in vitro EpiDerm ${ }^{\mathrm{TM}}$ skin
After $1 \mathrm{~h}$, the removal of thiolated CS-MNs loaded tacrolimus has increased erythema score.

No edema was exhibited

An elevated quantity of needles might cause these symptoms, which could be parallel to the increases in the number of pores per unit area of skin.

The blue dot matrix was found on the surface of rat skin after being washed with a saline solution.

No any inflammation and irritation occurs

The dye could not penetrate the $\mathrm{SC}$, but it can stain the inner tissue through the microholes generated in the skin layer.
The cell morphology of each layer was found to be normal after the exhibition of the test. inhibition ability almost similar to 5-Fu and showed a better inhibition at $48 \mathrm{~h}$.

No MN array-related damage or inflammation was found for up to 3 days.

No noticeable weight loss

No erythema and swelling

The cell viabilities were all above $90 \%$ at the 1:20, 2:20, and 3:20 mass ratio of (sucrose/PEGDA), which is significantly higher than the viability of those incubated with MNs made of pristine PEGDA or PEGDA plus fibrin scaffold.

No noticeable tissue lesion took place in this study.

The pores created by MNs were much greater (disappeared at $24 \mathrm{~h}$ after application) than the one pore created by subcutaneous injection (remained visible even at $72 \mathrm{~h}$ after).

The skin irritation test showed that No irritation occurs and no inflammatory reaction were found.

MNs have exhibited no obvious cytotoxicity without NIR laser.

[140]

No obvious irritant reaction

No irritation and inflammation occur.

No toxicity and inflammation in the major organs were exhibited

No obvious irritative reaction

No cytotoxic reaction occurs

No cytotoxic reaction and irritation occur.

No inflammation glycol)-polycaprolactone can a good carrier for 5-Fu delivery.

Because of the microemulsion, the

[142] Becausine constant subcutaneous distribution obtained, which resulted in the diminishing the toxicity

The monomethoxy-poly(ethylene

It showed biosynthetic Gel-MA- $\beta$ $\mathrm{CD} M N$ arrays were biocompatible with the skin and were potentially competent in sustained release of the drug.

It showed that amifostinearmored-MNs were a harmless technique used for active delivery.

It increased the convenience and acceptability for frequent administration of drugs or active agent using the MNs technique.

It confirmed that PEGDA/ sucrose MNs exhibited good biocompatibility, particularly after the incorporation of sucrose in the needle matrix.

It confirmed the hypo-toxicity and safety of as-fabricated MNs for potential clinical applications.

It confirmed that MNs' arrays did not cause serious skin damage or irritation, and they can be safe after application.

It proved that vismodegib [72] 
Table 4 In vivo and in vitro toxicity of MNs on a different model (Continued)

\begin{tabular}{|c|c|c|c|c|c|}
\hline $\begin{array}{l}\text { Sr. } \\
\text { No. }\end{array}$ & Study & Observation & Toxicity effect & Result/inference & Ref. \\
\hline & $\begin{array}{l}\text { irritation experiment on the EPI- } \\
\text { 200-SIT (reconstructed human epi- } \\
\text { dermal model EpiDerm) has been } \\
\text { conducted to examine the irri- } \\
\text { tancy level of vismodegib solution. }\end{array}$ & $\begin{array}{l}\text { the vismodegib solution was non- } \\
\text { irritant to the reconstructed hu- } \\
\text { man epidermal model EpiDerm. }\end{array}$ & & $\begin{array}{l}\text { formulation could be used safely } \\
\text { on animal skin with no irritation } \\
\text { to the application side. }\end{array}$ & \\
\hline 12. & $\begin{array}{l}\text { The cytotoxicity of rapamycin- } \\
\text { dissolving MNs were carried out } \\
\text { on HUVECs, Cell counting Kit-8 } \\
\text { assay. }\end{array}$ & $\begin{array}{l}\text { The viability of HUVECs incubated } \\
\text { vehicle dissolving MNs was higher } \\
\text { than } 80 \% \text {. }\end{array}$ & No cytotoxicity & $\begin{array}{l}\text { It showed the better } \\
\text { biocompatibility of the dissolving } \\
\text { MNs. }\end{array}$ & [19] \\
\hline 13. & $\begin{array}{l}\text { The lipid bilayer-coated with } \\
\text { antigen-loaded } \mathrm{mSiO}_{2}-\mathrm{NPs} \text { (LB- } \\
\text { MSNOVA) for intradermal antigen } \\
\text { delivery via coating } \mathrm{MN} \text { arrays had } \\
\text { tested for toxicity study. }\end{array}$ & $\begin{array}{l}\text { The MNs can undergo hydrolysis } \\
\text { to form a nontoxic by-product. } \\
\text { The intravenously injected MNs } \\
\text { were mainly excreted out of mice } \\
\text { through urine and faces. }\end{array}$ & No cytotoxic reaction. & $\begin{array}{l}\text { It shows that the developed MNs } \\
\text { are biodegradable and safe for } \\
\text { use. }\end{array}$ & {$[20]$} \\
\hline \multicolumn{6}{|c|}{ MNs showed in vivo and in vitro toxicity } \\
\hline 14. & $\begin{array}{l}\text { The dissolving MNs patch was } \\
\text { successively applied on depilated } \\
\text { mice's back skin and physiological } \\
\text { saline the negative control }\end{array}$ & $\begin{array}{l}\text { It was observed that the dissolving } \\
\text { MNs containing } \beta \text {-sodium } \\
\text { Glycerol-phosphate and hydroxy- } \\
\text { propyl } \beta \text {-cyclodextrin induced } \\
\text { slight mechanical damage. }\end{array}$ & $\begin{array}{l}\text { The histopathological } \\
\text { tissue section was } \\
\text { exhibited. The mild } \\
\text { inflammation in the cell } \\
\text { infiltration is seen in the } \\
\text { dermis. }\end{array}$ & $\begin{array}{l}\text { The skin irritation caused because } \\
\text { of dissolving MNs has mild and } \\
\text { transient. }\end{array}$ & [136] \\
\hline 15. & $\begin{array}{l}\text { The mice group was } \\
\text { transcutaneously treated with Ex4- } \\
\text { loaded MN patch. }\end{array}$ & $\begin{array}{l}\text { In this study, they induced the } \\
\text { MNs patch administration and } \\
\text { observed inflammatory reaction in } \\
\text { comparison with intradermal } \\
\text { injection of dual mineralized } \\
\text { particles. }\end{array}$ & $\begin{array}{l}\text { A slight inflammation } \\
\text { reaction occurs }\end{array}$ & $\begin{array}{l}\text { The less invasiveness of the MNs } \\
\text { patch to the skin suggested that } \\
\text { the Ex4-MNs patch is a highly bio- } \\
\text { compatible treatment. }\end{array}$ & [84] \\
\hline 16. & $\begin{array}{l}\text { The skin irritation after the } \\
\text { successful application of } \\
\text { alendronate-loaded MN array was } \\
\text { calculated using the Draize } \\
\text { method. }\end{array}$ & $\begin{array}{l}\text { At } 24 \text {, the irritation score after the } \\
\text { application of a blank MN array } \\
\text { was not changed. Besides, the } \\
\text { light erythema of the skin was } \\
\text { observed } 4 \text { and } 8 \text { days after a } 24 \mathrm{~h} \\
\text { application of a microneedle array. }\end{array}$ & $\begin{array}{l}\text { Slight erythema and } \\
\text { edema and irritation } \\
\text { occurs }\end{array}$ & $\begin{array}{l}\text { Further, studies are needed to } \\
\text { improve the safety of } \\
\text { alendronate-loaded MN array. In } \\
\text { this study, alendronate-induced } \\
\text { skin irritation can avoid by incorp- } \\
\text { orating antioxidants in the alen- } \\
\text { dronate MNs. }\end{array}$ & [21] \\
\hline
\end{tabular}

\section{$\mathrm{MN}$-approved products}

Despite the availability of plentiful fabrication strategies, the admirable scalability and reproducibility of the formulation is a major concern because of the nonavailability of regulatory guidance on manufacturing requirements of MNs and subsequent validation of process to assure uniformity of quality product. And as a formulation scientist, these issues related to fabrication majorly remains unanswered. In recent times, numerous safety trials on admirable applications of MNs for drugs, cosmetics, proteins, peptides, and vaccines among small population groups provide the basis for successful commercialization of a range of MN-based products [156]. Out of them, many are successfully coming into the market and approved by the government for medical and cosmetic purposes [157]. Interestingly, MNs present significant merits over the conventionally applied formulation in terms of delivery of activities to the targeted site or systemic delivery. Owing to this, from the past decade, there has been high growth in scientific and industrial activity in this field [14]. It is groundbreaking that the derma roller was the first approved MN-based product [12]. In the present review, we have enlisted some approved products (Table 7) of many companies $[12,49,156-158]$.

\section{Biosafety of MNs}

The system is based on MNs having plentiful pharmaceuticals along with biomedical applications. Owing to this, the optimization of $\mathrm{MN}$ formulation is gaining more importance for their successful utilization (Fig. 6b) [45]. It has been used to deliver the active agent into the selected side painlessly and safely [159]. Regardless of the benefits of MNs, the challenges about safety and biocompatibility are still acting as a barrier for development $[12,159]$. As per literature, the drug-loaded MNs remain innocuous [12], but some of them are unsafe and may be dangerous to tissue and body part. The application of MNs has a chance to cause skin irritation, tissue necrosis, and redness of the skin which can convert into severe infection and damage the part of the body [12, 45]. Besides this, many reports claimed the considerable 
Table 5 An updated summary of MN patents

\begin{tabular}{|c|c|c|c|c|}
\hline $\begin{array}{l}\text { Sr. } \\
\text { No. }\end{array}$ & $\begin{array}{l}\text { Publication } \\
\text { number }\end{array}$ & Conditions or diseases & Description/summary & Ref. \\
\hline 1. & $\begin{array}{l}13 / 2019 \\
201811044930\end{array}$ & Electrochemical biosensing in body fluid & $\begin{array}{l}\text { In this invention, it has developed a modern method for MNs } \\
\text { that prints assembled screens. Electrode fixes the biosensing } \\
\text { electrode to print the screen that sensing of blood glucose, } \\
\text { cholesterol HbA1C and like. }\end{array}$ & [22] \\
\hline 2. & $\begin{array}{l}48 / 2018 \\
201721017985\end{array}$ & $\begin{array}{l}\text { Treatment of hyperkeratosis, injury, and pain in } \\
\text { conditions like warts, corns, calluses, acne, psoriasis, } \\
\text { keloids, microtrauma, eczema }\end{array}$ & $\begin{array}{l}\text { The MNs patches based topical drug delivery system } \\
\text { incorporated with keratolytic agents. The patch comprises } \\
\text { micron-scale protrusions that penetrate via the SC and de- } \\
\text { livers the active pharmaceutical ingredient across the SC to } \\
\text { improve the permeation of drugs. A keratolytic agent reduces } \\
\text { the intercellular cohesiveness of the horny cells and thus en- } \\
\text { ables speedy shedding of keratinized cells. }\end{array}$ & [23] \\
\hline 3. & $\begin{array}{l}42 / 2018 \\
2017201721013027\end{array}$ & Management of anxiety & $\begin{array}{l}\text { In this patent novel, the buspirone microemulsion method } \\
\text { has developed using the phase titration method and tested } \\
\text { for its efficiency in the skin. It enhances transdermal delivery. }\end{array}$ & [24] \\
\hline 4. & WO/2010/013601 & Enhancement of immunogenicity & $\begin{array}{l}\text { It has enhanced immunogenicity using an MNs for the } \\
\text { Japanese encephalitis virus antigen derived from kidney cells } \\
\text { of monkey and concluded that antibody against a Japanese } \\
\text { encephalitis virus antigen has efficiently enhanced. }\end{array}$ & [146] \\
\hline 5. & WO/2010/001671 & $\begin{array}{l}\text { Enhancing the immunogenicity against influenza } \\
\text { virus }\end{array}$ & $\begin{array}{l}\text { Polylactic acid-coated MNs of an influenza vaccine that is the } \\
\mathrm{H}_{1} \mathrm{~N}_{1} \text { strain, } \mathrm{H}_{3} \mathrm{~N}_{2} \text { and types B strain, and brought into direct } \\
\text { skin contact that enhances immunogenicity against influenza } \\
\text { virus. }\end{array}$ & [147] \\
\hline 6. & 20150290163 & To treat pimples, stains, or wrinkles & $\begin{array}{l}\text { MNs contains a substrate, water-swelling polymer, and retin- } \\
\text { oic acid. It dissolves in an enormous amount of water. }\end{array}$ & [148] \\
\hline 7. & 20200170940 & Local anesthesia & $\begin{array}{l}\text { The invention provides immediate acting local anesthetic } \\
\text { MNs easily applied to the oral cavity or site, In which a } \\
\text { needle part dissolves in a mucous membrane when applying } \\
\text { to an oral mucous membrane or gums. }\end{array}$ & [149] \\
\hline 8. & 20170209553 & Botulinum toxin to treat diseases & $\begin{array}{l}\text { To treat disease, disorder, or condition therapeutic amount of } \\
\text { toxin was added to the MN array }\end{array}$ & [150] \\
\hline 9. & 20100030100 & Diagnosis of allergy & $\begin{array}{l}\text { This is an invention of a diagnostic MN device for the } \\
\text { detection of an allergy. It holds at least one allergen that } \\
\text { enables to perform skin tests with an effortless process in the } \\
\text { diagnosis of allergies. These MNs have been prepared using } \\
\text { non-metallic synthetic or natural resin material. }\end{array}$ & [151] \\
\hline
\end{tabular}

safety of MN-based drug, protein, and peptide drug delivery via the original route such as a transdermal route [12]. Also, there are claims for MN toxicity depending on the kind of materials utilized [21], the drug delivery approach [77], and the shape or dimensions of MNs [142]. Besides, the insertion of MNs through the skin can produce inflammation because of the breakdown of cells and produces free radicals that cause skin damage $[65,129]$. However, there are few biosafety conflicts that have not yet been settled. Some studies showed significant findings, which boost confidence regarding the utilization of MNs in pharmaceutical applications as well as and biomedical applications [12, 14, 144]. The toxicity of MN-based applications can reduce through the relevant use of the drug delivery approach, types of materials used, and release of drug from MNs. The toxicity of MNs can also be controlled through maintaining the bio-distribution and circulation time of drugs. The dosedependent toxicity can be monitored by innovative and suitable material and types of MNs. Concisely, the dose can be customized, which resulted in the maximum benefits, and subsequently, toxicity can be avoided.

\section{Expert opinion}

As per the recent decade's research headway with rapid advancement in technology, the MNs are gaining significant attention from researchers. It is noteworthy that the MNs comprise various nontoxic materials and can extensively be applied for effective transdermal, ophthalmic, and nasal delivery. Based on a survey of the various databases, the future of the MNs seems perspicuous and it is worth informative that the number of scientific fraternities is actively working on $\mathrm{MN}$ advancement. Owing to this, with the upcoming challenges of MNs, the numbers of research teams and publication counts are rapidly rising in recent years. From its inception, the successive clinical application of the MNs paves the alternative pathways that show a positive impact on the clinical (pharmaceutical or biomedical or cosmeceutical) and untimely patient's compliance. Besides, this major 
Table 6 MN product clinical trials completed (Source: ClinicalTrials.gov)

\begin{tabular}{ll}
\hline $\begin{array}{l}\text { Sr. } \\
\text { No. }\end{array}$ & Study title \\
\hline 1. & 2010/2011 trivalent influenza vaccination \\
2. & A study to assess the safety and efficacy of an MNs device for \\
local anesthesia
\end{tabular}

4. A pilot study to assess the safety, PK and PD of insulin injected via MicronJet or conventional needle

5. A study to assess the safety and efficacy of an MNs device for local anesthesia

6. Dose sparing intradermal S-OIV H1N1 influenza vaccination device

7. Routes of immunization and flu immune responses

8. A pilot study to evaluate the safety and immunogenicity of low dose flu vaccines

9. Insulin delivery using MNs in type 1 diabetes

10. Safety demonstration of $M N$ insertion

11. The use of MNs in photodynamic therapy

12. Site selection for intracutaneous saline delivery

13. Intracutaneous delivery of varied dose volumes of saline

14. The use of MNs with topical botulinum toxin for the treatment of palmar hyperhidrosis

15. Fractional MNs radiofrequency and I Botulinum Toxin A for primary axillary hyperhidrosis

16. Suprachoroidal injection of triamcinolone acetonide in subjects with macular edema following non-infectious uveitis

17. Glucose measurement using MN patches

18. Suprachoroidal injection of CLS-TA alone or with aflibercept in subjects with diabetic macular edema

19. A split-mouth trial to compare MNs vs. standard needles in dental anesthetic delivery

20. The effect of MN pretreatment on topical anesthesia
Intervention

Condition

Status

Year

- Biological: TIV 2010/2011

influenza vaccine

- Biological: INT

Device: MicronJet

- Medical device: MNs BD 1.5 mm 30G

- Drug: Tubertest ${ }^{\oplus:}$ : tuberculin

(purified protein derivative)

- Device: medical device:

lance $26 \mathrm{G} \times 16 \mathrm{~mm}$

- Drug: Tubertest ${ }^{\oplus}$

- Device: MicronJet

Device: Micron Jet

- Biological: S-OIV $\mathrm{H}_{1} \mathrm{~N}_{1}$ vaccine

- Biological: INTANZA ${ }^{\oplus 15}$

- Biological: Vaxigrip ${ }^{\oplus}$

- Biological: INTANZA ${ }^{\oplus 15}$ T

- Biological: Flu Vaccine (FLUARIX ${ }^{\circledast}$ )

Device: MNs

Device: Subcutaneous insulin catheter

Device: Gold- or silver-coated, or uncoated nickel MNs

Device: MNs

Drug: Aminolevulinic Acid Radiation: Blue light

- Device: Injection to deltoid

- Device: Injection to forearm

- Device: Injection to thigh

- Device: FLUGEN 101.2 device

Device: MNs

Device: Sham MNs

Drug: Botulinum Toxin Type A Other: Saline

Device: Fractional MNs

Radiofrequency

- Drug: 4 mg CLS-TA

- Drug: $0.8 \mathrm{mg}$ CLS-TA

Device: MNs patch

Device: Intravenous (IV)

catheter

Device: Lancet

- Drug: IVT Aflibercept

- Drug: SC CLS-TA

Device: MNs Device

(Experimental)

Device: 30-gauge Short Hypodermic Needle

Device: Sham MNs Roller Device: MNs Roller
Influenza

Completed 2011

Local anesthesia

Completed 2013

Intradermal injections

Completed 2013

Healthy volunteers

Intradermal injections

Completed 2013

Local anesthesia

Intradermal injections

Completed 2013

Influenza infection

Completed 2013

Influenza

Completed 2013

Influenza

Completed 2013

Type 1 diabetes

mellitus

Completed 2014

Allergic reaction to nickel

Completed 2016

Actinic keratosis

Completed 2017

- Intracutaneous drug delivery

Completed 2017

Influenza

Completed 2017

Hyperhidrosis

Completed 2017

Primary axillary

Completed 2017 hyperhidrosis

Uveitis, macular edema Completed 2017 Uveitis

Diabetes

Completed 2018

Diabetic macular

Completed 2018 edema

Dental pain

Anesthesia

Completed 2018

Pain

Completed 2018 
Table 6 MN product clinical trials completed (Source: ClinicalTrials.gov) (Continued)

\begin{tabular}{|c|c|c|c|c|c|}
\hline $\begin{array}{l}\text { Sr. } \\
\text { No. }\end{array}$ & Study title & Intervention & Condition & Status & Year \\
\hline 21. & MNs lesion preparation prior to ALA-PDT for AK on face & $\begin{array}{l}\text { - Drug: Aminolevulinic acid } \\
\text { - Drug: Topical Solution } \\
\text { Vehicle } \\
\text { - Device: IBL } 10 \mathrm{~mW}\end{array}$ & Actinic keratosis & Completed & 2018 \\
\hline 22. & $\begin{array}{l}\text { Clinical evaluation of healthy subjects receiving intradermal saline } \\
\text { using the MN adapter (Model UAR-2S) }\end{array}$ & $\begin{array}{l}\text { - Device: MNs Adapter (Model } \\
\text { UAR-2S) } \\
\text { - Device: Hypodermic needle } \\
\text { + syringe }\end{array}$ & Intradermal injection & Completed & 2018 \\
\hline 23. & $\begin{array}{l}\text { Safety and efficacy of ZP-zolmitriptan intracutaneous MN systems } \\
\text { for the acute treatment of migraine }\end{array}$ & $\begin{array}{l}\text { - Drug: ZP-Zolmitriptan } \\
\text { - Drug: Placebo }\end{array}$ & Acute migraine & Completed & 2018 \\
\hline 24. & $\begin{array}{l}\text { Suprachoroidal injection of CLS-TA in subjects with macular } \\
\text { edema associated with non-infectious uveitis. }\end{array}$ & $\begin{array}{l}\text { - Drug: } 4 \text { mg CLS-TA Supra- } \\
\text { choriodal Injection } \\
\text { - Drug: Sham Procedure }\end{array}$ & Uveitis, posterior uveitis & Completed & 2018 \\
\hline 25. & $\begin{array}{l}\text { A study to evaluate the long-term safety of M207 in the acute } \\
\text { treatment of migraine }\end{array}$ & - Drug: $\mathrm{M}_{2} \mathrm{O}_{7}$ MNs System & Migraine & Completed & 2019 \\
\hline 26. & $\begin{array}{l}\text { The use of MNs to expedite treatment time in photodynamic } \\
\text { therapy }\end{array}$ & $\begin{array}{l}\text { - Device: MN roller } \\
\text { - Drug: Aminolevulinic acid } \\
\text { - Radiation: Blue Light }\end{array}$ & Keratosis, actinic & Completed & 2019 \\
\hline 27. & $\begin{array}{l}\text { A study of the use of MN patches to deliver topical lidocaine in } \\
\text { the oral cavity }\end{array}$ & $\begin{array}{l}\text { - Device: MNs Patch } \\
\text { - Device: Patch with no MNs }\end{array}$ & Topical anesthesia & Completed & 2019 \\
\hline 28. & $\begin{array}{l}\text { Inactivated influenza vaccine delivered by MN patch or by } \\
\text { hypodermic needle }\end{array}$ & $\begin{array}{l}\text { - Biological: Inactivated } \\
\text { influenza vaccine } \\
\text {. Other: Placeb }\end{array}$ & Influenza & Completed & 2019 \\
\hline 29. & $\begin{array}{l}\text { Safety study of suprachoroidal triamcinolone acetonide via MN to } \\
\text { treat uveitis }\end{array}$ & $\begin{array}{l}\text { - Drug: Triamcinolone } \\
\text { acetonide }\end{array}$ & $\begin{array}{l}\text { Uveitis, intermediate } \\
\text { uveitis, posterior uveitis }\end{array}$ & Completed & 2019 \\
\hline 30. & $\begin{array}{l}\text { Extension study of patients with non-infectious uveitis who par- } \\
\text { ticipated in CLS1001-301 }\end{array}$ & $\begin{array}{l}\text { - Drug: } 4 \text { mg CLS-TA Supra- } \\
\text { choriodal Injection }\end{array}$ & $\begin{array}{l}\text { Uveitis } \\
\text { Posterior uveitis }\end{array}$ & Completed & 2019 \\
\hline 31. & $\begin{array}{l}\text { Suprachoroidal injection of CLS-TA in subjects with non- } \\
\text { infectious uveitis }\end{array}$ & $\begin{array}{l}\text { - Combination Product: } 4 \text { mg } \\
\text { CLS-TA }\end{array}$ & $\begin{array}{l}\text { Uveitis } \\
\text { Posterior uveitis }\end{array}$ & Completed & 2019 \\
\hline 32. & $\begin{array}{l}\text { Analysis of noninvasively collected MN device samples from mild } \\
\text { plaque psoriasis for use in transcriptomics profiling }\end{array}$ & - Device: MN device & Psoriasis vulgaris & Completed & 2019 \\
\hline 33. & $\begin{array}{l}\text { Comparison of 1,550-nm laser and fractional radiofrequency MNs } \\
\text { for the treatment of acne scars in ethnic skin }\end{array}$ & $\begin{array}{l}\text { - Device: Fraxel Restore } \\
\text { - Device: Fractora }\end{array}$ & Acne scars & Completed & 2019 \\
\hline 34. & Minimally invasive sensing of beta-lactam antibiotics & $\begin{array}{l}\text { - Drug: Phenoxymethyl } \\
\text { Penicillin } \\
\text { - Device: MN array }\end{array}$ & Healthy volunteers & Completed & 2019 \\
\hline 35. & Pain and safety of MNs in the oral cavity & $\begin{array}{l}\text { Other: MNs } \\
\text { Other: Hypodermic needle } \\
\text { Other: Flat patch }\end{array}$ & Oral cavity disease & Completed & 2019 \\
\hline 36. & MNs patch study in healthy infants/young children & $\begin{array}{l}\text { Device: MNs Formulation } 1 \\
\text { Device: MNs Formulation } 2\end{array}$ & $\begin{array}{l}\text { Vaccination } \\
\text { Skin absorption }\end{array}$ & Completed & 2020 \\
\hline
\end{tabular}

milestone of translation of MNs from research to clinical trial and, finally, into the patient application, necessitates good science, engineering, and significant funding from government agencies and pharmaceutical industries. In a nutshell, the appropriate number of financial support can resolve the economic issue and it will pave the way to $\mathrm{MN}$ product development and its clinical trial. We witnessed that we are suffering more challenges to translate the research into new medicinal products, which can provide improvement in patients. Out of various concerns, the development of economic, scalable, and trustworthy manufacturing of the MN-based product, and its real-time benefit to the patient health improvement is still the major challenge to researchers. Concisely, the uncertainties are present with the beginning of any innovative medical technology. It includes the targeted administration of a lower dose of drug/vaccine in humans or animals via MNs without irritation with the predefined rate (slow or fast uptake into the blood). The animal immunogenic response provided by MNs and human immunology might show the same or different or smaller amount of responses. Besides, when the active 
Table 7 MNs approved product for pharmaceutical applications

\begin{tabular}{|c|c|c|c|c|}
\hline Product name & Manufactured by & $\begin{array}{l}\text { Types of } \\
\text { MNs }\end{array}$ & Specifications & Applications \\
\hline Dermaroller ${ }^{\oplus}$ & $\begin{array}{l}\text { Dermaroller } \\
\text { Germany, White } \\
\text { Lotus }\end{array}$ & $\begin{array}{l}\text { Solid or } \\
\text { metal MNs, }\end{array}$ & $\begin{array}{l}\text { Cylindrical roller shape and } 0.2 \mathrm{~mm} \text { to } 2.5 \mathrm{~mm} \text { in } \\
\text { length }\end{array}$ & $\begin{array}{l}\text { Use to improve skin texture and } \\
\text { treatment of scars and } \\
\text { hyperpigmentation. }\end{array}$ \\
\hline Dermaroller $^{\mathrm{TM} M S-4}$ & $\begin{array}{l}\text { The Dermaroller } \\
\text { Series: Anastassakis } \\
\text { K }\end{array}$ & - & $\begin{array}{l}\text { Small cylinder, } 1 \mathrm{~cm} \text { length, } 2 \mathrm{~cm} \text { in diameter, } 4 \\
\text { circular arrays of needles (total } 96 \text { needles) }\end{array}$ & Use to treatment on facial acne scars \\
\hline MicroHyala ${ }^{\oplus}$ & $\begin{array}{l}\text { CosMED } \\
\text { Pharmaceutical Co. } \\
\text { Ltd }\end{array}$ & $\begin{array}{l}\text { Dissolvable } \\
\text { MNs }\end{array}$ & $\begin{array}{l}\text { Slowly dissolved } \\
\text { Less irritating }\end{array}$ & Use to wrinkle treatment \\
\hline h-patch & Valeritas & - & A small adhesive machine like the patch is used & $\begin{array}{l}\text { To deliver drugs (insulin) in } \\
\text { subcutaneous }\end{array}$ \\
\hline $\begin{array}{l}\text { Microstructured } \\
\text { transdermal } \\
\text { system }\end{array}$ & $3 \mathrm{M}$ & $\begin{array}{l}\text { Hollow } \\
\text { MNs }\end{array}$ & - & $\begin{array}{l}\text { To deliver biologics and other small } \\
\text { molecules }\end{array}$ \\
\hline $\begin{array}{l}\text { Dermaroller }{ }^{\mathrm{TM}} \text { MF-8 } \\
\text { type }\end{array}$ & $\begin{array}{l}\text { The Dermaroller } \\
\text { Series: Anastassakis } \\
\text { K }\end{array}$ & - & A needle length of $1.5 \mathrm{~mm}(1500 \mu \mathrm{m})$ & Used for the treatment of scars \\
\hline $\begin{array}{l}\text { CIT-8 (collagen } \\
\text { induction therapy }\end{array}$ & $\begin{array}{l}\text { The Dermaroller } \\
\text { Series: Anastassakis } \\
\text { K }\end{array}$ & - & A needle length of $0.5 \mathrm{~mm}(500 \mu \mathrm{m})$ & $\begin{array}{l}\text { Used in collagen induction and skin } \\
\text { remodeling }\end{array}$ \\
\hline LiteClear $^{\oplus}$ & Nanomed skincare & $\begin{array}{l}\text { Solid silicon } \\
\text { MNs }\end{array}$ & - & $\begin{array}{l}\text { Utilized to treats acne and skin } \\
\text { blemishes }\end{array}$ \\
\hline $\begin{array}{l}\text { Dermaroller }{ }^{\mathrm{TM}} \mathrm{C}-8 \\
\text { (Cosmetic type) }\end{array}$ & $\begin{array}{l}\text { The Dermaroller } \\
\text { Series: Anastassakis } \\
\text { K }\end{array}$ & - & $\begin{array}{l}\text { A needle length of } 0.13 \mathrm{~mm}(130 \mu \mathrm{m}), 24 \text { circular } \\
\text { arrays of } 8 \text { needles each (total } 192 \text { needles) }\end{array}$ & $\begin{array}{l}\text { Used to enhance the penetration rate of } \\
\text { topical agents }\end{array}$ \\
\hline BD Soluvia ${ }^{\circledast}$ & $\begin{array}{l}\text { BD, Sanofi Pasteur } \\
\text { Europe }\end{array}$ & $\begin{array}{l}\text { Hollow } \\
\text { MNs }\end{array}$ & 1.5-mm-long hypodermic needle & Used for Influenza vaccination \\
\hline
\end{tabular}

administration via MNs in a large population is set as a contrast to the clinical trial, the finding of a clinical trial in a controlled environment may or may not be like the outcomes from a larger population in the normal daily condition of individual patients. Owing to the advanced technology, the daily use of MNs can require more practice. Despite this, pharmaceutical industries have confidential mass production methods due to competitive interest and this might be a major barrier for the progress of innovative MNs. Thus, from a future point of view, it is a primary requirement to develop cost-effective, reliable MNs on a large scale through the current good manufacturing practice. To overcome the abovementioned concerns, it is desirable to convince industries and research groups for advancing the MN research arena. Many of $\mathrm{MN}$ products are under the initial phase of 3 clinical trials, which can be launched as a modern pathway for the management of numerous ailments. Additionally, day by day, the interest of the pharmaceutical industry in MN product development is rapidly increasing and the milestone of cosmetic MNs is encouraging to the patient for MN applications. Therefore, in upcoming years, the smart new MN product can pave the bright prospect for the pharmaceutical industry.

\section{Conclusion}

Even though multiple drug delivery systems continue to be introduced on a nanoscale designed for the targeted delivery of active substances, MNs are unique because of their versatile properties and characteristics. In the active pharmaceutical ingredient delivery using MNs, it has provided the pioneering way out for life-threatening illnesses. The MNs have already verified to be more proficient and a safe alternative to earlier reported methods of drug delivery systems. The present review provides insight into fabrication materials and methods used for MN synthesis. The role of MNs in serving as a platform to treat various ailments has been explained by unusual approaches. Moreover, the review also inculcates the pharmacokinetics of MNs, which includes permeation, absorption, and bioavailability enhancement. Besides this, the in vitro/in vivo toxicity, biosafety, and marketed product of MNs have been reviewed. Overall, the application of MNs has gained lots of attention and an enormous amount of ongoing research works; we can be soon observing various groundbreaking commercial applications in the management of various health issues. Besides, findings obtained in synthesis, functionalization (with active agent/s), and the design of MNs have led extensively to promising advances in 
different fields. The FDA for clinical application has already permitted a few products, and many more are under clinical trials. The notable achievement of these smart MNs for numerous clinical appliances paves the evolutionary pathway for active agent-based MNs for clinical use. MNs have been used for drug/vaccine delivery by skin penetration in the preceding decade. The plentiful research literature has demonstrated the importance of MNs in therapeutic applications through a different route of administration. Similar to its counterpart, MNs possess unique and versatile properties, which can be explored for various pharmaceutical and biomedical patents. The ability to deliver active agent(s) to the targeted site with improved pharmacokinetics and bring about higher safety and efficacy further makes it a most effective platform for pharmaceutical and biomedical applications. The MNs can be further investigated, and advances in the utilization of MNs in the different challenging fields can be further promoted. Inclusively, the most recent $\mathrm{MN}$ investigations have revealed a precise beneficial forecast of whatever manufacturing is in store for the future of medicine.

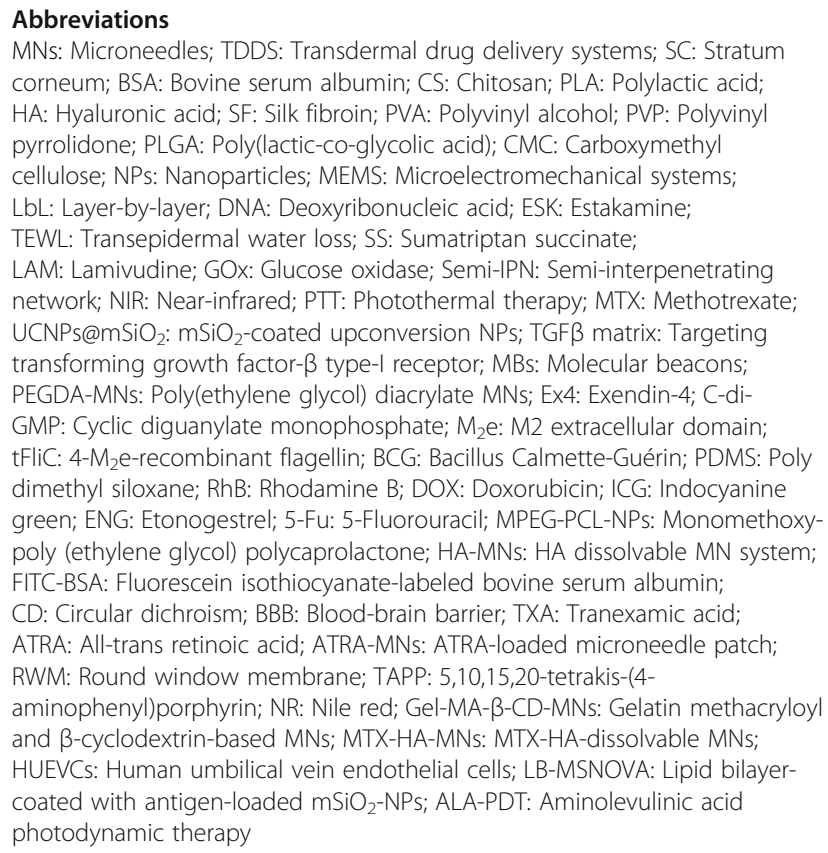

\section{Acknowledgements}

The authors are thankful to the institute for providing facilities such as a library, journals, and internet sources for writing the article.

\section{Authors' contributions}

SN: conceptualization, methodology, writing-original draft, writing-review and editing, visualization; SD: writing —original draft, writing-review and editing. All authors gave their individual critical revision and final approval of the version to be submitted. RT: writing-original draft, writing-review and editing. All authors gave their individual critical revision and final approval of the version to be submitted. RD: writing —original draft, writing_review and editing. All authors gave their individual critical revision and final approval of the version to be submitted.
Funding

Not applicable

Availability of data and materials

All data and materials are available on request.

Ethics approval and consent to participate

Not applicable

\section{Consent for publication}

Not applicable

\section{Competing interests}

The authors declare that they have no conflict of interest.

\section{Author details}

${ }^{1}$ Department of Pharmaceutical Sciences and Technology, Institute of Chemical Technology, Matunga, Mumbai, Maharashtra 400019, India. ${ }^{2}$ Department of Pharmaceutical Chemistry, H. R. Patel Institute of Pharmaceutical Education and Research, Shirpur-425405, Dhule, Maharashtra, India. ${ }^{3}$ Department of Pharmaceutics, Annasaheb Dange College of D. Pharmacy, Ashta-416301, Sangli, Maharashtra, India.

Received: 23 October 2020 Accepted: 29 December 2020

Published online: 13 January 2021

\section{References}

1. Kulkarni MP, Kiran PSS, Reddy KVP (2018) Microneedles: a review on painless micro injections. Int J Res Pharm Pharm Sci 3(2):38-42

2. Nangare S, Tade RS, Dugam S, Shitole MM (2020) Progress in erectile dysfunction therapy via drug delivery system. Thai J Pharm Sci 44(2):73-81

3. Barry BW (2001) Novel mechanisms and devices to enable successful transdermal drug delivery. Eur J Pharm Sci 14(2):101-114

4. Tabassum N, Sofi A, Khuroo T (2011) Microneedle technology: a new drug delivery system. Int J Res Pharmaceut Biomed Sci 2(1):59-62

5. Donnelly RF, Singh TRR, Woolfson AD (2010) Microneedle-based drug delivery systems: microfabrication, drug delivery, and safety. Drug Deliv 17(4):187-207

6. Mogusala NR, Devadasu VR, Venisetty RK (2015) Fabrication of microneedle molds and polymer based biodegradable microneedle patches: a novel method. Am J Drug Deliv Ther 2(2):60-71

7. Serrano-Castañeda P, Escobar-Chávez JJ, Rodríguez-Cruz IM, Melgoza LM, Martinez-Hernandez J (2018) Microneedles as enhancer of drug absorption through the skin and applications in medicine and cosmetology. Pharm Pharm Sci 21:73-93

8. Prausnitz MR, Mitragotri S, Langer R (2004) Current status and future potential of transdermal drug delivery. Nat Rev Drug Discov 3(2):115-124

9. Xiang Z, Wang H, Pastorin G, Lee C (2015) Development of a flexible and disposable microneedle-fluidic-system with finger-driven drug loading and delivery functions for inflammation treatment. J Microelectromech Syst 24(3):565-574

10. Xie L, Zeng H, Sun J, Qian W (2020) Engineering microneedles for therapy and diagnosis: a survey. Micromachines 11(3):271

11. Du G, Sun X (2020) Current advances in sustained release microneedles. Pharmaceutical Fronts 2(01):e11-e22

12. Waghule T, Singhvi G, Dubey SK, Pandey MM, Gupta G, Singh M, Dua K (2019) Microneedles: a smart approach and increasing potential for transdermal drug delivery system. Biomed Pharmacother 109:1249-1258

13. Verbaan F, Bal S, Van den Berg D, Groenink W, Verpoorten H, Lüttge R, Bouwstra J (2007) Assembled microneedle arrays enhance the transport of compounds varying over a large range of molecular weight across human dermatomed skin. J Control Release 117(2):238-245

14. Larraneta E, Lutton RE, Woolfson AD, Donnelly RF (2016) Microneedle arrays as transdermal and intradermal drug delivery systems: materials science, manufacture and commercial development. Mater Sci Eng R Rep 104:1-32

15. Hong X, Wei L, Wu F, Wu Z, Chen L, Liu Z, Yuan W (2013) Dissolving and biodegradable microneedle technologies for transdermal sustained delivery of drug and vaccine. Drug Des Devel Ther 7:945-952

16. Badran M, Kuntsche J, Fahr A (2009) Skin penetration enhancement by a microneedle device (Dermaroller ${ }^{\circledR}$ ) in vitro: dependency on needle size and applied formulation. Eur J Pharm Sci 36(4-5):511-523 
17. Donnelly RF, Morrow DI, Singh TR, Migalska K, McCarron PA, O'Mahony C, Woolfson AD (2009) Processing difficulties and instability of carbohydrate microneedle arrays. Drug Dev Ind Pharm 35(10):1242-1254

18. Nguyen HX, Banga AK (2015) Enhanced skin delivery of vismodegib by microneedle treatment. Drug Deliv Trans Res 5(4):407-423

19. Mao J, Wang H, Xie Y, Fu Y, Li Y, Liu P, Du H, Zhu J, Dong L, Hussain M (2020) Transdermal delivery of rapamycin with poor water-solubility by dissolving polymeric microneedles for anti-angiogenesis. J Mater Chem B 8: 928-934

20. Tu J, Du G, Nejadnik MR, Mönkäre J, van der Maaden K, Bomans PH, Sommerdijk NA, Slütter B, Jiskoot W, Bouwstra JA (2017) Mesoporous silica nanoparticle-coated microneedle arrays for intradermal antigen delivery. Pharm Res 34(8):1693-1706

21. Katsumi H, Liu S, Tanaka Y, Hitomi K, Hayashi R, Hirai Y, Kusamori K, Y-s Q, Kamiyama F, Sakane T (2012) Development of a novel self-dissolving microneedle array of alendronate, a nitrogen-containing bisphosphonate: evaluation of transdermal absorption, safety, and pharmacological effects after application in rats. J Pharm Sci 101(9):3230-3238

22. Prem Chandra Pandey GP, Narayan RJ (2019) A process for making microneedle-based transdermal biosensor involving poyethyleniminemodified prussian blue-gold nanohybrids-enzyme ink for on-chip electrochemical biosensing in body fluid. Intellect Property India: 201811044930

23. Majumdar Anuradha DS (2018) Matrix type microneedle patches containing keratolytic agents. Intellect Property India 2018:201721017985

24. Patel DJ (2018) Microneedle assisted transdermal delivery of buspirone. Intellect Property India 2018:201721013027

25. Ding Z, Verbaan FJ, Bivas-Benita M, Bungener L, Huckriede A, van den Berg DJ, Kersten G, Bouwstra JA (2009) Microneedle arrays for the transcutaneous immunization of diphtheria and influenza in BALB/C mice. J Control Release 136(1):71-78

26. Martanto W, Davis SP, Holiday NR, Wang J, Gill HS, Prausnitz MR (2004) Transdermal delivery of insulin using microneedles in vivo. Pharm Res 21(6): 947-952

27. Cormier M, Johnson B, Ameri M, Nyam K, Libiran L, Zhang DD, Daddona P (2004) Transdermal delivery of desmopressin using a coated microneedle array patch system. J Control Release 97(3):503-511

28. Gill HS, Prausnitz MR (2007) Coating formulations for microneedles. Pharm Res 24(7):1369-1380

29. Bhatnagar S, Chawla SR, Kulkarni OP, Venuganti WK (2017) Zein microneedles for transcutaneous vaccine delivery: fabrication, characterization, and in vivo evaluation using ovalbumin as the model antigen. ACS Omega 2(4):1321-1332

30. Miyano T, Tobinaga Y, Kanno T, Matsuzaki Y, Takeda H, Wakui M, Hanada K (2005) Sugar micro needles as transdermic drug delivery system. Biomed Microdevices 7(3):185-188

31. Kolli CS, Banga AK (2008) Characterization of solid maltose microneedles and their use for transdermal delivery. Pharm Res 25(1):104-113

32. Su L-C, Chen M-C (2017) Efficient delivery of nanoparticles to deep skin layers using dissolvable microneedles with an extended-length design. J Mater Chem B 5(18):3355-3363

33. Ye R, Yang J, Li Y, Zheng Y, Yang J, Li Y, Liu B, Jiang L (2020) Fabrication of tip-hollow and tip-dissolvable microneedle arrays for transdermal drug delivery. ACS Biomaterials Science \& Engineering 6(4):2487-2494

34. Martanto W, Moore JS, Kashlan O, Kamath R, Wang PM, O'Neal JM, Prausnitz MR (2009) Microinfusion using hollow microneedles. Pharm Res 23(1):104-113

35. Jiang J, Moore JS, Edelhauser HF, Prausnitz MR (2009) Intrascleral drug delivery to the eye using hollow microneedles. Pharm Res 26(2):395-403

36. Wang PM, Cornwell M, Hill J, Prausnitz MR (2006) Precise microinjection into skin using hollow microneedles. J Invest Dermatol 126(5):1080-1087

37. Hutton AR, McCrudden MT, Larrañeta E, Donnelly RF (2020) Influence of molecular weight on transdermal delivery of model macromolecules using hydrogel-forming microneedles: potential to enhance the administration of novel low molecular weight biotherapeutics. J Mater Chem B 8(19):4202-4209

38. Courtenay AJ, McAlister E, McCrudden MT, Vora L, Steiner L, Levin G, LevyNissenbaum E, Shterman N, Kearney M-C, McCarthy HO (2020) Hydrogelforming microneedle arrays as a therapeutic option for transdermal esketamine delivery. J Control Release 2020

39. Chen S, Matsumoto H, Moro-oka Y, Tanaka M, Miyahara Y, Suganami T, Matsumoto A (2019) Smart microneedle fabricated with silk fibroin combined semi-interpenetrating network hydrogel for glucose-responsive insulin delivery. ACS Biomater Sci Eng 5(11):5781-5789

40. Li J, Liu B, Zhou Y, Chen Z, Jiang L, Yuan W, Liang L (2017) Fabrication of a Ti porous microneedle array by metal injection molding for transdermal drug delivery. PLoS One 12(2):e0172043

41. Li S, Li W, Prausnitz M (2018) Individually coated microneedles for codelivery of multiple compounds with different properties. Drug Deliv Transl Res 8(5):1043-1052

42. Pamornpathomkul B, Niyomtham N, Yingyongnarongkul B-E, Prasitpuriprecha C, Rojanarata T, Ngawhirunpat T, Opanasopit P (2008) Cationic niosomes for enhanced skin immunization of plasmid DNA-encoding ovalbumin via hollow microneedles. AAPS PharmSciTech 19(1):481-488

43. William A, Barry B (2004) Penetration enhancer. Adv Drug Deliv 56:603-618

44. Gittard S, Narayan R, Jin C, Ovsianikov A, Chichkov B, Monteiro-Riviere N, Stafslien S, Chisholm B (2009) Pulsed laser deposition of antimicrobial silver coating on Ormocer ${ }^{\circledast}$ microneedles. Biofabrication 1(4):041001

45. Cheung K, Das DB (2016) Microneedles for drug delivery: trends and progress. Drug Deliv 23(7):2338-2354

46. Chen B, Wei J, Tay FE, Wong YT, lliescu C (2008) Silicon microneedle array with biodegradable tips for transdermal drug delivery. Microsyst Technol 14(7):1015-1019

47. Sharma D (2018) Microneedles: an approach in transdermal drug delivery: a Review. PharmaTutor 6(1):7-15

48. O'Mahony C (2014) Structural characterization and in-vivo reliability evaluation of silicon microneedles. Biomed Microdevices 16(3):333-343

49. Li J, Zeng M, Shan $H$, Tong C (2017) Microneedle patches as drug and vaccine delivery platform. Curr Med Chem 24(22):2413-2422

50. Uppuluri C, Shaik AS, Han T, Nayak A, Nair KJ, Whiteside BR, Nalluri BN, Das DB (2017) Effect of microneedle type on transdermal permeation of rizatriptan. AAPS PharmSciTech 18(5):1495-1506

51. Manoj VR, Manoj H (2019) Review on transdermal microneedle-based drug delivery. Asian J Pharm Clin Res 12(1):18-29

52. Queiroz MLB, Shanmugam S, Santos LNS, Campos CdA, Santos AM, Batista MS, Araújo AAdS, Serafini MR (2020) Microneedles as an alternative technology for transdermal drug delivery systems: a patent review. Expert Opin Ther Pat 30(6):433-452

53. Moffatt K, Wang Y, Singh TRR, Donnelly RF (2017) Microneedles for enhanced transdermal and intraocular drug delivery. Curr Opin Pharmacol 36:14-21

54. Narayanan SP, Raghavan S (2019) Fabrication and characterization of goldcoated solid silicon microneedles with improved biocompatibility. Int J Adv Manuf Technol 104(9-12):3327-3333

55. Thakur RRS, Tekko IA, Al-Shammari F, Ali AA, McCarthy H, Donnelly RF (2016) Rapidly dissolving polymeric microneedles for minimally invasive intraocular drug delivery. rug. Deliv Transl Res 6(6):800-815

56. Gilger BC, Abarca EM, Salmon JH, Patel S (2013) Treatment of acute posterior uveitis in a porcine model by injection of triamcinolone acetonide into the suprachoroidal space using microneedles. Invest Ophthalmol Vis Sci 54(4):2483-2492

57. Chiu WS, Belsey NA, Garrett NL, Moger J, Price GJ, Delgado-Charro MB, Guy RH (2015) Drug delivery into microneedle-porated nails from nanoparticle reservoirs. J Control Release 220:98-106

58. Aksit A, Rastogi S, Nadal ML, Parker AM, Lalwani AK, West AC, Kysar JW (2020) Drug delivery device for the inner ear: ultra-sharp fully metallic microneedles. Drug Delive Trans Res. https://doi.org/10.1007/s13346-02000782-9

59. Nangare S, Dhananjay B, Mali R, Shitole M (2019) Development of novel freeze-dried mulberry leaves extract-based transfersomal gel. Turk J Pharm Sci. https://doi.org/10.4274/tjps.98624

60. Park J-H, Allen MG, Prausnitz MR (2005) Biodegradable polymer microneedles: fabrication, mechanics and transdermal drug delivery. J Control Release 104(1):51-66

61. Migalska K, Morrow DI, Garland MJ, Thakur R, Woolfson AD, Donnelly RF (2011) Laser-engineered dissolving microneedle arrays for transdermal macromolecular drug delivery. Pharm Res 28(8):1919-1930

62. Wu D, Y-s Q, Kamiyama F, Kusamori K, Katsumi H, Sakane T, Yamamoto A (2015) Improvement of transdermal delivery of sumatriptan succinate using a novel self-dissolving microneedle array fabricated from sodium hyaluronate in rats. Biol Pharm Bull 38(3):365-373

63. Jain S, Tiwary AK, Sapra B, Jain NK (2007) Formulation and evaluation of ethosomes for transdermal delivery of lamivudine. AAPS PharmSciTech 8(4):249 
64. Ramadan E, Borg T, Abdelghani G, Saleh NM (2016) Transdermal microneedlemediated delivery of polymeric lamivudine-loaded nanoparticles. J Pharm Technol Drug Res 5(1). https://doi.org/10.7243/2050-120X-5-1

65. Lhernould MS (2013) Optimizing hollow microneedles arrays aimed at transdermal drug delivery. Microsyst Technol 19(1):1-8

66. Heinemann $L$ (2011) New ways of insulin delivery. Int J Clin Pract 65:31-46

67. Zhang Y, Yu J, Kahkoska AR, Wang J, Buse JB, Gu Z (2019) Advances in transdermal insulin delivery. Adv Drug Deliv Rev 139:51-70

68. Pillai O, Panchagnula R (2001) Insulin therapies-past, present and future. Drug Discov Today 6(20):1056-1061

69. Gordijo CR, Koulajian K, Shuhendler AJ, Bonifacio LD, Huang HY, Chiang S, Ozin GA, Giacca A, Wu XY (2011) Nanotechnology-enabled closed loop insulin delivery device: In vitro and in vivo evaluation of glucose-regulated insulin release for diabetes control. Adv Funct Mater 21(1):73-82

70. Mo R, Jiang T, Di J, Tai W, Gu Z (2014) Emerging micro- and nanotechnology based synthetic approaches for insulin delivery. Chem Soc Rev 43(10):3595-3629

71. Yu J, Zhang Y, Gu Z (2017) Glucose-responsive insulin delivery by microneedle-array patches loaded with hypoxia-sensitive vesicles. Methods Mol Biol 1570:251-259

72. Liu D, Zhang Y, Jiang G, Yu W, Xu B, Zhu J (2018) Fabrication of dissolving microneedles with thermal-responsive coating for NIR-triggered transdermal delivery of metformin on diabetic rats. ACS Biomater Sci Eng 4(5):1687-1695

73. Yu W, Jiang G, Zhang Y, Liu D, Xu B, Zhou J (2017) Polymer microneedles fabricated from alginate and hyaluronate for transdermal delivery of insulin. Mater Sci Eng C 80:187-196

74. Gomaa YA, Garland MJ, Mclnnes F, El-Khordagui LK, Wilson C, Donnelly RF (2012) Laser-engineered dissolving microneedles for active transdermal delivery of nadroparin calcium. Eur J Pharm Biopharm 82(2):299-307

75. Wermeling DP, Banks SL, Hudson DA, Gill HS, Gupta J, Prausnitz MR, Stinchcomb AL (2008) Microneedles permit transdermal delivery of a skinimpermeant medication to humans. Proc Natl Acad Sci 105(6):2058-2063

76. Kim D, Kim H, Lee PC, Lee JB (2020) Universally applicable RNA membranebased microneedle system for transdermal drug delivery. Mater Horiz 7(5): $1317-1326$

77. Leachman SA, Hickerson RP, Schwartz ME, Bullough EE, Hutcherson SL, Boucher KM, Hansen CD, Eliason MJ, Srivatsa GS, Kornbrust DJ (2010) Firstin-human mutation-targeted siRNA phase Ib trial of an inherited skin disorder. Mol Ther 18(2):442-446

78. Shi N-Q, Qi X-R, Xiang B, Zhang Y (2014) A survey on "Trojan Horse" peptides: opportunities, issues and controlled entry to "Troy". J Control Release 194:53-70

79. Wang M, Han Y, Yu X, Liang L, Chang H, Yeo DC, Wiraja C, Wee ML, Liu L, Liu X (2020) Upconversion nanoparticle powered microneedle patches for transdermal delivery of siRNA. Adv Healthc Mater 9(2):1900635

80. Deng Y, Chen J, Zhao Y, Yan X, Zhang L, Choy K, Hu J, Sant HJ, Gale BK, Tang $T$ (2016) Transdermal delivery of siRNA through microneedle array. Sci Rep 6:21422

81. Ali AA, McCrudden CM, McCaffrey J, McBride JW, Cole G, Dunne NJ, Robson T, Kissenpfennig A, Donnelly RF, McCarthy HO (2017) DNA vaccination for cervical cancer; a novel technology platform of RALA mediated gene delivery via polymeric microneedles. Nanomedicine 13(3):921-932

82. Correia M, Neves-Petersen MT, Jeppesen PB, Gregersen S, Petersen SB (2012) UV-light exposure of insulin: pharmaceutical implications upon covalent insulin dityrosine dimerization and disulphide bond photolysis. PLoS One 7(12): 550733

83. Liu S, Yeo DC, Wiraja C, Tey HL, Mrksich M, Xu C (2017) Peptide delivery with poly (ethylene glycol) diacrylate microneedles through swelling effect. Bioeng Transla Med 2(3):258-267

84. Chen W, Tian R, Xu C, Yung BC, Wang G, Liu Y, Ni Q, Zhang F, Zhou Z, Wang J (2017) Microneedle-array patches loaded with dual mineralized protein/peptide particles for type 2 diabetes therapy. Nat Commun 8(1): $1-11$

85. Zhang S, Qiu Y, Gao Y (2014) Enhanced delivery of hydrophilic peptides in vitro by transdermal microneedle pretreatment. Acta Pharm Sin B 4(1): 100-104

86. Hauri AM, Armstrong GL, Hutin YJ (2004) The global burden of disease attributable to contaminated injections given in health care settings. Int J STD AIDS 15(1):7-16

87. Wang L, Coppel RL (200) Oral vaccine delivery: can it protect against nonmucosal pathogens? Expert Rev Vaccines 7(6):729-738
88. Lambert PH, Laurent PE (2008) Intradermal vaccine delivery: will new delivery systems transform vaccine administration? Vaccine 26(26):3197-3208

89. Marshall S, Sahm LJ, Moore AC (2016) The success of microneedle-mediated vaccine delivery into skin. Hum Vaccin Immunother 12(11):2975-2983

90. Shin J-H, Lee J-H, Jeong SD, Noh J-Y, Lee HW, Song C-S, Kim Y-C (2020) C-diGMP with influenza vaccine showed enhanced and shifted immune responses in microneedle vaccination in the skin. Drug Delive Trans Res:1-11

91. Duong HTT, Kim NW, Thambi T, Phan VG, Lee MS, Yin Y, Jeong JH, Lee DS (2018) Microneedle arrays coated with charge reversal pH-sensitive copolymers improve antigen presenting cells-homing DNA vaccine delivery and immune responses. J Control Release 269:225-234

92. Zhu W, Pewin W, Wang C, Luo Y, Gonzalez GX, Mohan T, Prausnitz MR, Wang B-Z (2017) A boosting skin vaccination with dissolving microneedle patch encapsulating M2e vaccine broadens the protective efficacy of conventional influenza vaccines. J Control Release 261:1-9

93. Hirobe S, Azukizawa H, Hanafusa T, Matsuo K, Quan Y-S, Kamiyama F, Katayama I, Okada N, Nakagawa S (2015) Clinical study and stability assessment of a novel transcutaneous influenza vaccination using a dissolving microneedle patch. Biomaterials 57:50-58

94. Edens C, Collins ML, Goodson JL, Rota PA, Prausnitz MR (2015) A microneedle patch containing measles vaccine is immunogenic in nonhuman primates. Vaccine 33(37):4712-4718

95. Hiraishi Y, Nandakumar S, Choi S-O, Lee JW, Kim Y-C, Posey JE, Sable SB, Prausnitz MR (2011) Bacillus Calmette-Guerin vaccination using a microneedle patch. Vaccine 29(14):2626-2636

96. Vrdoljak A, McGrath MG, Carey JB, Draper SJ, Hill AV, O'Mahony C, Crean AM, Moore AC (2012) Coated microneedle arrays for transcutaneous delivery of live virus vaccines. J Control Release 159(1):34-42

97. Park J, Ye M, Park K (2005) Biodegradable polymers for microencapsulation of drugs. Molecules 10(1):146-161

98. Gao Y, Hou M, Yang R, Zhang L, Xu Z, Kang Y, Xue P (2019) Highly porous silk fibroin scaffold packed in PEGDA/sucrose microneedles for controllable transdermal drug delivery. Biomacromolecules 20(3):1334-1345

99. He M, Yang G, Zhao X, Zhang S, Gao Y (2020) Intradermal implantable PLGA microneedles for etonogestrel sustained release. J Pharm Sci 109(6):1958-1966

100. Liu G-S, Kong Y, Wang Y, Luo Y, Fan X, Xie X, Yang B-R, Wu MX (2020) Microneedles for transdermal diagnostics: recent advances and new horizons. Biomaterials 232:119740

101. Uddin MJ, Scoutaris N, Economidou SN, Giraud C, Chowdhry BZ, Donnelly RF, Douroumis D (2020) 3D printed microneedles for anticancer therapy of skin tumours. Mater Sci Eng C 107:110248

102. Tham HP, Xu K, Lim WQ, Chen H, Zheng M, Thng TGS, Venkatraman SS, Xu C, Zhao Y (2018) Microneedle-assisted topical delivery of photodynamically active mesoporous formulation for combination therapy of deep-seated melanoma. ACS Nano 12(12):11936-11948

103. Hao Y, Chen Y, He X, Yang F, Han R, Yang C, Li W, Qian Z (2020) Nearinfrared responsive 5-fluorouracil and indocyanine green loaded MPEG-PCL nanoparticle integrated with dissolvable microneedle for skin cancer therapy. Bioact Mater 5(3):542-552

104. Jain S, Patel N, Shah MK, Khatri P, Vora N (2017) Recent advances in lipidbased vesicles and particulate carriers for topical and transdermal application. J Pharm Sci 106(2):423-445

105. Wang M, Hu L, Xu C (2017) Recent advances in the design of polymeric microneedles for transdermal drug delivery and biosensing. Lab Chip 17(8): 1373-1387

106. Vora LK, Courtenay AJ, Tekko IA, Larrañeta E, Donnelly RF (2020) Pullulanbased dissolving microneedle arrays for enhanced transdermal delivery of small and large biomolecules. Int J Biol Macromol 146:290-298

107. Yorio T, Clark A (2011) Wax MB (2011) Ocular therapeutics: eye on new discoveries: academic press

108. Qazi Y, Maddula S, Ambati BK (2009) Mediators of ocular angiogenesis. J Genet 88(4):495-515

109. Lee SS, Hughes P, Ross AD, Robinson MR (2010) Biodegradable implants for sustained drug release in the eye. Pharm Res 27(10):2043-2053

110. Ranta V-P, Urtti A (2006) Transscleral drug delivery to the posterior eye: prospects of pharmacokinetic modeling. Adv Drug Deliv Rev 58(11):1164-1181

111. Ghate D, Edelhauser HF (2006) Ocular drug delivery. Expert Opin Drug Deliv 3(2):275-287

112. Than A, Liu C, Chang H, Duong PK, Cheung CMG, Xu C, Wang X, Chen P (2018) Self-implantable double-layered micro-drug-reservoirs for efficient and controlled ocular drug delivery. Nat Commun 9(1):4433 
113. Khandan O, Kahook MY, Rao MP (2016) Fenestrated microneedles for ocular drug delivery. Sensors Actuators B Chem 223:15-23

114. Kim YC, Edelhauser HF, Prausnitz MR (2014) Targeted delivery of antiglaucoma drugs to the supraciliary space using microneedles. Invest Ophthalmol Vis Sci 55(11):7387-7397

115. Daneman R, Prat A (2015) The blood-brain barrier. Cold Spring Harb Perspect Biol 7(1):a020412

116. Upadhyay RK $(2014$, 2014) Drug delivery systems, CNS protection, and the blood brain barrier. Biomed Res Int. https://doi.org/10.1155/2014/869269

117. Agrawal L, Vimal SK, Chen M-H, Shiga T (2018) An idea of using microneedles for the targeted drug delivery to overcome the blood brain barrier for the treatment of brain diseases. Aust J Pharm. https://doi.org/10. 4172/2329-6887.54-001

118. Kearney M-C, Caffarel-Salvador E, Fallows SJ, McCarthy HO, Donnelly RF (2016) Microneedle-mediated delivery of donepezil: potential for improved treatment options in Alzheimer's disease. Eur J Pharm Biopharm 103:43-50

119. Lee HJ, Son Y, Kim D, Kim YK, Choi N, Yoon E-S, Cho I-J (2015) A new thin silicon microneedle with an embedded microchannel for deep brain drug infusion. Sensors Actuators B Chem 209:413-422

120. El-Laboudi A, Oliver NS, Cass A, Johnston D (2013) Use of microneedle array devices for continuous glucose monitoring: a review. Diabetes Technol Ther 15(1):101-115

121. Cha KJ, Kim T, Park SJ, Kim DS (2014) Simple and cost-effective fabrication of solid biodegradable polymer microneedle arrays with adjustable aspect ratio for transdermal drug delivery using acupuncture microneedles. J Micromech Microeng 24(11):115015

122. Mishra RK, Mohan AV, Soto F, Chrostowski R, Wang J (2017) A microneedle biosensor for minimally-invasive transdermal detection of nerve agents. Analyst 142(6):918-924

123. Sharma S, El-Laboudi A, Reddy M, Jugnee N, Sivasubramaniyam S, El Sharkawy M, Georgiou P, Johnston D, Oliver N, Cass AE (2018) A pilot study in humans of microneedle sensor arrays for continuous glucose monitoring. Anal Methods 10:2088-2095

124. Gowers SA, Freeman DM, Rawson TM, Rogers ML, Wilson RC, Holmes AH, Cass AE, O'Hare D (2019) Development of a minimally invasive microneedlebased sensor for continuous monitoring of $\beta$-lactam antibiotic concentrations in vivo. ACS Sensors 4(4):1072-1080

125. Wang R, Jiang X, Wang W, Li Z (2017) A microneedle electrode array on flexible substrate for long-term EEG monitoring. Sensors Actuators B Chem 244:750-758

126. Sharma S, Takagi E, Cass T, Tsugawa W, Sode K (2017) Minimally invasive microneedle array electrodes employing direct electron transfer type glucose dehydrogenase for the development of continuous glucose monitoring sensors. Procedia Manuf 27:208-209

127. Skoog SA, Miller PR, Boehm RD, Sumant AV, Polsky R, Narayan RJ (2015) Nitrogen-incorporated ultrananocrystalline diamond microneedle arrays for electrochemical biosensing. Diam Relat Mater 54:39-46

128. Keum DH, Jung HS, Wang T, Shin MH, Kim YE, Kim KH, Ahn GO, Hahn SK (2015) Microneedle biosensor for real-time electrical detection of nitric oxide for in situ cancer diagnosis during endomicroscopy. Adv Healthc Mater 4(8):1153-1158

129. Machekposhti SA, Soltani M, Najafizadeh P, Ebrahimi SA, Chen P (2017) Biocompatible polymer microneedle for topical/dermal delivery of tranexamic acid. J Control Release 261:87-92

130. Hirobe S, Otsuka R, lioka H, Quan Y-S, Kamiyama F, Asada H, Okada N, Nakagawa S (2017) Clinical study of a retinoic acid-loaded microneedle patch for seborrheic keratosis or senile lentigo. Life Sci 168:24-27

131. Doddaballapur S (2009) Microneedling with dermaroller. J Cutan Aesthet Surg 2(2):110-111

132. Seo KY, Kim DH, Lee SE, Yoon MS, Lee HJ (2013) Skin rejuvenation by microneedle fractional radiofrequency and a human stem cell conditioned medium in Asian skin: a randomized controlled investigator blinded splitface study. J Cosmet Laser Ther 15(1):25-33

133. Chandrashekar B, Yepuri V, Mysore V (2014) Alopecia areata-successful outcome with microneedling and triamcinolone acetonide. J Cutan Aesthet Surg 7(1):63-64

134. Alsantali A (2011) Alopecia areata: a new treatment plan. Clin Cosmet Investig Dermatol 4:107-115

135. Al Faraj A, Shaik AS, Al Sayed B (2015) Preferential magnetic targeting of carbon nanotubes to cancer sites: noninvasive tracking using MRI in a murine breast cancer model. Nanomedicine 10(6):931-948
136. Yao G, Quan G, Lin S, Peng T, Wang Q, Ran H, Chen H, Zhang Q, Wang L, Pan X (2017) Novel dissolving microneedles for enhanced transdermal delivery of levonorgestrel: In vitro and in vivo characterization. Int J Pharm 534(1-2):378-386

137. Permana AD, Mir M, Utomo E, Donnelly RF (2020) Bacterially sensitive nanoparticle-based dissolving microneedles of doxycycline for enhanced treatment of bacterial biofilm skin infection: a proof of concept study. Int J Pharm 2020:119220

138. Karchemski F, Zucker D, Barenholz Y, Regev O (2012) Carbon nanotubesliposomes conjugate as a platform for drug delivery into cells. J Control Release 160(2):339-345

139. Yu X, Li M, Zhu L, Li J, Zhang G, Fang R, Wu Z, Jin Y (2020) Amifostineloaded armored dissolving microneedles for long-term prevention of ionizing radiation-induced injury. Acta Biomater:2020

140. Ahmad Z, Khan MI, Siddique MI, Sarwar HS, Shahnaz G, Hussain SZ, Bukhari $\mathrm{NI}$, Hussain I, Sohail MF (2020) Fabrication and characterization of thiolated chitosan microneedle patch for transdermal delivery of tacrolimus. AAPS PharmSciTech 21(2):1-12

141. Cheng Z, Lin H, Wang Z, Yang X, Zhang M, Liu X, Wang B, Wu Z, Chen D (2020) Preparation and characterization of dissolving hyaluronic acid composite microneedles loaded micelles for delivery of curcumin. Drug Deliv Trans Res 2020:1-11

142. Zhang Y, Hu H, Jing Q, Wang Z, He Z, Wu T, Feng N-P (2020) Improved biosafety and transdermal delivery of aconitine via diethylene glycol monoethyl ether-mediated microemulsion assisted with microneedles. Pharmaceutics 12(2):163

143. Zhou X, Luo Z, Baidya A, Hj K, Wang C, Jiang X, Qu M, Zhu J, Ren L, Vajhadin F (2020) Biodegradable $\beta$-cyclodextrin conjugated gelatin methacryloyl microneedle for delivery of water-insoluble drug. Adv Healthc Mater:2000527

144. Du H, Liu P, Zhu J, Lan J, Li Y, Zhang L, Zhu J, Tao J (2019) Hyaluronic acidbased dissolving microneedle patch loaded with methotrexate for improved treatment of psoriasis. ACS Appl Mater Interfaces 11(46):43588-43598

145. Liu S, Wu D, Y-s Q, Kamiyama F, Kusamori K, Katsumi H, Sakane T, Yamamoto A (2016) Improvement of transdermal delivery of exendin-4 using novel tip-loaded microneedle arrays fabricated from hyaluronic acid. Mol Pharm 13(1):272-279

146. Nozaki CK, Kazuyoshi MJ, Terahara T, Kuwahara T, Tokumoto S $(2010,2010)$ Microneedle device and method for enhancing the efficacy of Japanese encephalitis virus antigen with the microneedle device. WIPO Patent Application WO/2010/013601

147. Nozaki CK, Kazuyoshi MJ, Terahara T, Kuwahara T, Tokumoto S (2010, 2010, WO/2010/001671) Microneedle devise, and method for enhancing the efficacy of influenza vaccine by using microneedle device. WIPO Patent Application

148. Asada Y-SQFKMSNOSH (2014) (2014) Retinoic acid microneedle. European Patent Office, p EP2915557A1

149. Fumio QY-sK. Dental local anesthetic microneedle array. United States Patent Application. 2020;20200170940(May)

150. Speaker RLKT (2017) Delivery of botulinum with microneedle arrays. United States Patent Application Publication July 2017 US20170209553A1

151. Kuwahara STTMT (2010). Microneedle device for diagnosis of allergy. United States Patent Application Publication Feb 2010;US20100030100A1

152. Larrañeta E, McCrudden MT, Courtenay AJ, Donnelly RF (2016) Microneedles: a new frontier in nanomedicine delivery. Pharm Res 33(5):1055-1073

153. Prausnitz MR (2017) Engineering microneedle patches for vaccination and drug delivery to skin. Annu Rev Chem Biomol Eng 8:177-200

154. Hao Y, Li W, Zhou X, Yang F, Qian Z (2017) Microneedles-based transdermal drug delivery systems: a review. J Biomed Nanotechnol 13(12):1581-1597

155. Bariya SH, Gohel MC, Mehta TA, Sharma OP (2012) Microneedles: an emerging transdermal drug delivery system. J Pharm Pharmacol 64(1):11-29

156. Bora P, Kumar L, Bansal AK (2008) Microneedle technology for advanced drug delivery: Evolving vistas. Review Article, Department of Pharmaceutical Technology, NIPER, CRIPS 9(1)

157. Singh A, Yadav S (2016) Microneedling: advances and widening horizons. Indian Dermatol Online J 7(4):244-254

158. Anastassakis K (2005) The Dermaroller Series. Private Paper. 2005

159. He X, Sun J, Zhuang J, Xu H, Liu Y, Wu D (2019) Microneedle system for transdermal drug and vaccine delivery: devices, safety, and prospects. DoseResponse 17(4):1559325819878585

\section{Publisher's Note}

Springer Nature remains neutral with regard to jurisdictional claims in published maps and institutional affiliations. 